\title{
The impact of value perceptions on purchase intention of sustainable luxury brands in China and the UK
}

\author{
Pengji Wang ${ }^{1}\left(\mathbb{D} \cdot\right.$ Adrian T. H. Kuah $^{1} \cdot$ Qinye $^{\mathrm{Lu}^{2}} \cdot$ Caroline Wong $^{1} \cdot \mathrm{K}$. Thirumaran ${ }^{1} \cdot$ Emmanuel Adegbite $^{1,3}$. \\ Wesley Kendall ${ }^{4}$
}

Revised: 30 May 2020 / Accepted: 24 December 2020 / Published online: 30 January 2021

(C) The Author(s), under exclusive licence to Springer Nature Limited part of Springer Nature 2021

\begin{abstract}
Despite luxury brands' efforts to incorporate sustainable development into their branding and product design, studies have shown inconclusive evidence about consumers' reaction towards such efforts. This study investigates how consumption values (i.e. the need for exclusivity, conformity, and hedonism) affect consumers' acceptance of luxury brands' sustainable efforts. It adopts a cross-cultural framework by analysing two countries, namely China and the UK, which differ substantially in some of Hofstede's cultural dimensions, namely power distance, individualism, and indulgence. Using the structural equation modelling in analysing 677 survey responses from actual luxury goods' consumers in the two countries, we suggest that hedonic needs drive consumers' purchase intentions in China and the UK. We find that the need for exclusivity in sustainable luxury items is negatively related to consumers' purchase intentions in China, while the need for conformity is positively related. In contrast, these effects are reversed in the UK. Our study implies the need to align the marketing of sustainable luxury with consumption values of consumers to reflect the cultural differences. In theorizing sustainable luxury research, this study provides a deeper understanding of value perceptions pertaining to luxury product consumption and sustainability.
\end{abstract}

Keywords Sustainable practices $\cdot$ Luxury brands $\cdot$ Cross-culture $\cdot$ Consumer attitude

\section{Introduction}

Luxury brands are increasingly criticized for their unethical and unsustainable practices. This has led to some brands committing more to sustainable and socially responsible

Supplementary Information The online version contains supplementary material available at https://doi.org/10.1057/s4126 2-020-00228-0.

Pengji Wang

pengji.wang@jcu.edu.au

Adrian T. H. Kuah

adrian.kuah@jcu.edu.au

Qinye Lu

qinye.lu@dmu.ac.uk

Caroline Wong

caroline.wong@jcu.edu.au

K. Thirumaran

k.thirumaran@jcu.edu.au

Emmanuel Adegbite

Emmanuel.Adegbite@ nottingham.ac.uk;

emmanuel.adegbite@jcu.edu.au initiatives (Anido Freire and Loussaïef 2018; Mititelu et al. 2014). While there is increasing scholarly attention given to sustainable luxury research, a recent systematic review of literature between 2007 and 2018 revealed that few studies have sought to understand sustainability within the luxury marketplace (Athwal et al. 2019). The limited studies insufficiently addressed the compatibility between luxury and sustainability (De Angelis et al. 2017; Karaosman et al. 2020).

\section{Wesley Kendall}

wes.evankendall@gmail.com

1 JCU Singapore Business School, James Cook University, 149 Sims Drive, Singapore 387380, Singapore

2 Leicester Castle Business School, De Montfort University, Gateway House, Leicester LE1 9BH, UK

3 Nottingham University Business School, University of Nottingham, Jubilee Campus, Nottingham NG8 1BB, UK

4 James E Rogers College of Law, University of Arizona, Phnom Penh Campus, AUPP, Phnom Penh, Cambodia 
On the one hand, some studies (Davies et al. 2012; Achabou and Dekhili 2013; Dekhili et al. 2019) suggest that consumers give low priority to sustainability in luxury consumption and show less preference for buying luxury goods with sustainable materials. Indeed, about one-third of luxury buyers pointed out that luxury contradicts sustainability (Kapferer and Michaut-Denizeau 2017). On the other hand, other studies argued that some features of luxury goods can be aligned with the notion of sustainability. For instance, Janssen et al. (2014) suggested that the durability of luxury goods conveys a fit between sustainable use of resources and luxury. While this finding implies that sustainable luxury caters to the needs of functionality-oriented luxury consumers, it is not applicable to luxury consumers who purchase products for other reasons. The extant literature though insightful reveals conflicting results and an unresolved question relating to the extent to which luxury consumers are interested in the sustainable efforts of luxury brands. This gap in the literature is addressed in this paper.

In doing this, we focus on how different consumption values may affect consumers' acceptance of luxury brands' sustainable efforts. Many luxury consumers generally exhibit consumption values which include both personal and social values (Hennigs et al. 2012, 2015). The question, however, is whether these values are sufficient to motivate consumers to purchase luxury products when these luxury products or brands highlight their sustainable features and practices? If luxury consumption values do not motivate consumers, or, even worse, demotivate them from purchasing sustainable luxury products, we can then conclude that taking on sustainability will harm the luxury status of products. However, few studies have examined the impact of consumers' luxury values on their attitudes towards sustainable luxury. The only existing attempt is a descriptive and exploratory study by Cervellon and Shammas (2013), who used elicitation technique and interviewed European and Canadian consumers to show that several luxury values are enhanced through sustainability practices (e.g. durable quality, conspicuousness). Besides, Tynan et al. (2010) and Shukla (2011) have called for the empirical testing of value perceptions to extend the validity and reliability of the extant theory on luxury consumption.

In response, this paper empirically focuses on the UK and China, two important markets representing different stages of the luxury market (D'Arpizio et al. 2017). China is an emerging luxury market with the largest consumption power (Zhan and He 2012). China delivered more than half of the global growth in luxury spending between 2012 and 2018 and is expected to deliver $65 \%$ of the world's additional spending heading into 2025 (McKinsey and Company 2019). The UK is a mature market for luxury production and consumption, with average luxury purchasing per consumer estimated to reach $\$ 21,193$ in 2019 (Jaekel 2019). The two countries also differ substantially in the national cultural dimensions (Hofstede 2007), in that China scores higher in power distance but lower in individualism and indulgence than the UK. By examining the reactions of consumers to sustainable luxury in these two very different countries, we are responding to the call from Athwal et al. (2019) to highlight the imperatives of having an international perspective and a rigorous cross-cultural methodology to deal with the current empirical bias towards Western consumers in sustainable luxury research. In so doing, we also verify the similarity and differences in results and mechanisms found between Western and non-Western cultural contexts. We focus on three key consumption values in luxury goods, namely the need for exclusivity (Tian et al. 2001; Bian and Forsythe 2012), the need for conformity (Bearden et al. 1989; Zhan and He 2012), and the hedonic need of consumers (Wiedmann et al. 2009). Based on 677 survey respondents from China and the UK, we tested the impact of luxury consumers' commonly held values on their preferences for sustainable luxury.

We make original contributions to the literature. Firstly, by investigating and rigorously testing how three commonly held luxury values influence consumers' preferences for sustainable luxury over general luxury products, our study deepens the understanding of whether luxury and sustainability are compatible, and also answers the calls of Tynan et al. (2010) and Shukla (2011) for the rigorous empirical testing of value perceptions. In doing this, we augment the validity and reliability of the extant theory and literature on luxury consumption. Our study reveals that sustainable luxury could be appealing to luxury consumers who can associate sustainable features with guilty-free pleasure, uniqueness, and social trend. Such results support a compatibility view between luxury and sustainability, allowing us to forge ahead in the theorizing of sustainable luxury and in the framing of its marketing effort.

Second, in adopting a cross-cultural framework to explore our research inquiry, we contribute to cross-national sustainable luxury research by comparing consumers' reaction towards sustainable luxury in a less explored Chinese market and a more extensively investigated UK market. Athwal et al. (2019) in their literature review on sustainable luxury highlighted a significant lacuna in research on culture and sustainable luxury. Most studies on luxury consumption do not consider the ethical or sustainable aspect and those few examining sustainable luxury often use a monocultural framing (Athwal et al. 2019), for instance, focusing on France (Kapferer and Michaut-Denizeau 2014), Italy (Pencarelli et al. 2019), China (Zhan and He 2012; Siu et al. 2016; Filieri et al. 2019), or the UK (Davies et al. 2012). This study shows that although consumers across cultures may have similar motivations when purchasing general luxury goods, the motivations for sustainable luxury differ 
across the West and East. Our results thus provide insights into how luxury companies can address their sustainability efforts to influence consumers' purchasing decisions in culturally different countries. We proceed with a review of relevant literature, theory and hypotheses development, methodology, results, discussions, and finally contributions.

\section{Literature review}

\section{Sustainable luxury}

Scholarly research has begun documenting sustainability efforts of luxury brands (Athwal et al. 2019; Anido Freire and Loussaïef 2018; Han et al. 2017; Macchion et al. 2018; Mititelu et al. 2014), suggesting that incorporation of sustainability into luxury brands should not be ignored (Winston 2016). However, since the first mention of sustainable luxury as a separate construct by Bendell and Kleanthous's (2007), there has been an ongoing debate on whether the concept of luxury is even compatible with sustainability (Kapferer and Michaut-Denizeau 2014; Achabou and Dekhili 2013). To start with, the World Commission on Environment and Development defines sustainability as 'meeting the needs of the present without compromising the ability of future generations to meet their own needs' (Brundtland Report 1987, p. 8). This definition emphasizes the conservation of nature's assets in business and consumption practice. Nevertheless, luxury brands often strive for perfect quality and creativity, while disregarding costs (Kapferer 2010). Luxury derives from objective rarity (e.g. rare skins, rare leathers, rare pearls, rare materials, rare craftsmanship), which challenges biodiversity and animal welfare (Kapferer and Michaut-Denizeau 2014). In this way, such products are conflicting with necessity and often associated with over and unnecessary consumption. As a result, luxury brands are accused of wasting 'resources for the pleasure of a happy few' (Kapferer 2010, p. 40), representing an irrational and even immoral behaviour (Keinan et al. 2016). In addition, the inherent high prices notably highlight the inequality in society. In sum, luxury goods are associated with personal pleasure, superficiality, and ostentation, whereas sustainable development evokes altruism, sobriety, moderation, and ethics (Widloecher 2010).

Consistent with theoretical predictions, several empirical pieces of evidence show the incompatibility between luxury consumption and sustainability. For example, Bhattacharya and Sen (2004) reported that consumers support sustainability but are not ready to pay more for it. Ehrich and Irwin (2005) demonstrated consumers' tendency to purposefully ignore sustainability issues when they purchase, even though they say they are concerned. Davies et al. (2012) argued that ethical considerations weigh very little in consumers' luxury purchase calculations. Indeed, some research even find a negative correlation between luxury and sustainability. For example, Kapferer and Michaut-Denizeau (2014) found that luxury contradicts sustainable development when consumers perceive luxury as superficial and creating social unrest. In their study of French luxury buyers, the majority (52.8\%) believed that luxury should not be a priority for sustainable development activism. Achabou and Dekhili (2013) found that consumers perceive recycled material in luxury products negatively, even when they are convinced that recycling is beneficial for the environment. Consumers give much less consideration to sustainability than to other features when making a luxury purchase (Athwal et al. 2019). This prevalent view on consumers' reactions to luxury brands' sustainable efforts, together with these brands' new trend of engaging more with sustainability, raises a significant question. How can luxury brands align their sustainable efforts with the values commonly pursued by luxury consumers?

To address this question, some researchers have disaggregated the concept of sustainability into sub-components and shown that some components are aligned with luxury features. Janssen et al. (2014) found that durability, a component of sustainability, aligns well with consumers' requirement for luxury products and thus enhances product value. Cervellon and Shammas (2013) used elicitation technique with small-scale interview data from France, Italy, the UK, and Canada to show that several luxury values are enhanced through sustainable luxury (e.g. durable quality, conspicuousness). Their study provides preliminary insights, and we extend their work by focusing on three commonly held luxury values and rigorously testing how they influence consumers' preferences for sustainable luxury.

\section{Luxury values}

Luxury is an abstract concept whose meaning is determined by personal and interpersonal motives that make up the consumer's perceptions (Vigneron and Johnson 2004). Therefore, its definition and measurement tend to be subjective (De Barnier et al. 2012). Prior studies have attempted to categorize such subjective perceptions into values or needs. For example, Woodall (2003) conceptualized four distinct aspects of value: exchange value, use value, intrinsic value, and utilitarian value. Vigneron and Johnson (2004) distinguished luxury from non-luxury brands by introducing two major dimensions-namely personal perceptions, which entail perceived hedonic value and perceived extended self, and non-personal perceptions, which entail perceived conspicuousness, perceived uniqueness, and perceived quality. Wiedmann et al. (2009) extended these classifications using four latent dimensions of value-namely social (e.g. prestige and conspicuous), functional (e.g. usability, quality, and uniqueness), individual (e.g. self-identity, material, and 
hedonic), and financial (e.g. price). Berthon et al. (2009) conceptualized luxury goods as having three distinct valuebased dimensions: objective (material), subjective (individual), and collective (social). Smith and Colgate (2007) proposed another four dimensions critical to value creation-namely symbolic/expressive, experiential/hedonic, utilitarian/functional, and cost/sacrifice values.

As can be seen, the extant literature highlights several important and interrelated dimensions of luxury value. Thus, we deduce that, first, luxury value perceptions have a strong social dimension that accounts for both self and others. Second, important dimensions of luxury include personal experience and pleasure. Third, luxury goods are sought for their high quality and functionality and have an association with overall price perception. However, a caveat regarding this relates to when consumers overstate the importance of function and quality due to a 'functional alibi' to justify their purchase of expensive luxury products (Keinan et al. 2016). Therefore, the current study does not focus on this dimension of 'quality and functionality' but instead on personal and social dimensions.

\section{Luxury consumption in cross-cultural contexts}

Despite numerous cross-cultural studies being carried out on luxury consumption (e.g., Aliyev et al. 2018; Lee et al. 2018; Zhang et al. 2014 among others), much less research has been conducted to examine sustainable luxury consumption from an international perspective. In a recent systematic review of a decade of research on sustainable luxury, Athwal et al. (2019) highlighted a gap in the literature relating to the relationship between culture and sustainable luxury. They found that most of the studies on sustainable luxury focus on a single site or country; a disproportionately large amount of research has been conducted in the UK and France, while much less have examined the other significant markets such as East Asia. Among the small amount of research on multiple cultural contexts, the methodology used was dominated by appreciative inquiry (Bendell and Thomas 2013) or conceptual framework (Hennigs et al. 2015; Kapferer 2010), while rigorous empirical work is still lacking. There is room, therefore, for more cross-cultural comparison to offer robust insights into the potential differences between cultures and consumers' motives, behaviours, and attitudes towards sustainable luxury. This study responds to this need by empirically comparing consumers' reaction towards sustainable luxury in a less explored market such as China and a more extensively investigated UK market.

We built our comparison study based on Hofstede's cultural framework (1980), where China and the UK differ most substantially in three of six cultural dimensions, i.e. power distance ( 80 vs. 35 ), individualism-collectivism ( 20 vs. 89 ), and indulgence (24 vs. 69) (Hofstede Insights, nd). These three dimensions are also closely related to the three consumption values addressed in our study.

The dimension of power distance is closely related to consumers' needs for exclusivity. The exclusivity of a luxury product and its popularity in the social context are key mechanisms that drive their luxury purchasing, particularly for new emerging luxury buyers - the newly rich and middle class in China (Bazi et al. 2020; Rovai 2016). Having an opportunity to own a luxury product and live a luxury lifestyle enables them to step out of the lower-ranking social classes and emulate upper-class behaviours (Filieri and Lin 2017; Karaosman et al. 2020). Exclusivity, being closely related to an individual's appreciation for higher social status, could vary across high- and low-power-distance contexts, where expectation and acceptance of power inequality differ. As a result, power distance serves as a relevant cultural dimension for us to rely on to discuss the different impact of exclusivity in China and the UK.

The dimension of individualism-collectivism can be connected to consumers' need for conformity, which is another motivation for luxury consumers. The need for conformity aligns with an interdependent self-construal suggesting a more connected way to fit in with relevant others (Aliyev and Wagner 2018). The extent of interdependence and need to belong to a group and affiliation with other group members could be higher in collectivistic culture than in individualistic culture, because the former values interdependence more than the latter (Hofstede and Minkov 2010).

The dimension of indulgence is linked to hedonistic value in luxury consumption. The extant literature suggests that luxury purchases could also be related to personal choice where consumers satisfy individual's emotional needs to satisfy the private self (Aliyev and Wagner 2018; Rovai 2016), rather than the social needs. Such hedonistic value has been linked to sensory pleasure, satisfaction, and aesthetics (Fauchois and Krieg 1991; Roux and Floch 1996; Vigneron and Johnson 2004) and is deemed as important motivation for luxury consumption by both Western and Eastern consumers (Bian and Forsythe 2012). However, how much an individual pursues hedonic value (sensory pleasure) is shaped by cultural value related to indulgence, which is the extent to which a person tries to control his/her desires and impulses.

The foregoing motivates our study to examine how three commonly held values (i.e. exclusivity need, conformity need, and hedonic need) influence consumers' preferences for sustainable luxury in two culturally different contexts (China and the UK.) Ultimately, this study provides insights into whether luxury values and sustainability are at all compatible. In the next section, we present the theoretical framework and develop the hypotheses to examine whether luxury brands' sustainable efforts strengthen (or weaken) these luxury values. 
Fig. 1 Theoretical model

Individualists

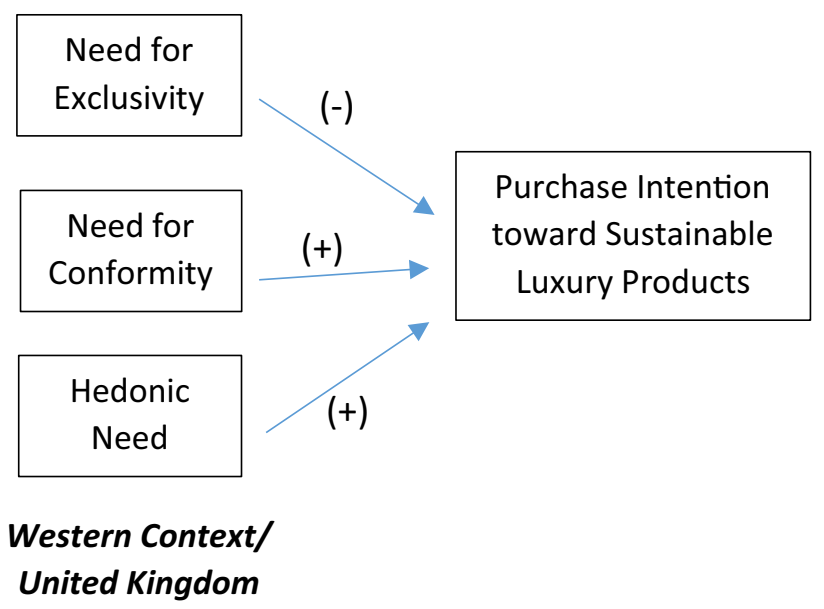

Collectivists

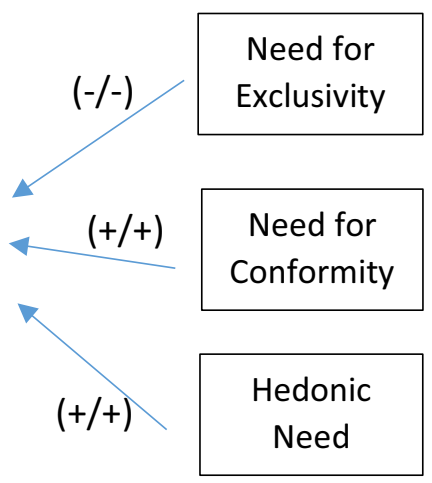

Eastern Context/ China

\section{Theory and hypotheses development}

Social value perceptions are outer-directed consumption preferences related to impression management (Goffman 1959). They represent the perceived utility of symbolism and image, in associating or disassociating with demographic, socio-economic, and cultural-ethnic reference groups (Sheth et al. 1991; Shukla 2012; Shukla and Purani 2012). In this study, we focus on three social values, namely the need for exclusivity (Tian et al. 2001; Bian and Forsythe 2012), the need for conformity (Bearden et al. 1989; Zhan and He 2012), and hedonic needs or the perception of emotional value derived from luxury brands, such as happiness or selfsatisfaction (Wiedmann et al. 2009). All three are important motivators for luxury consumption. Drawing on Hofstede's (1980) cultural framework, we argue that the way that these three luxury values influence the purchase of sustainable luxury goods varies across China and UK. Figure 1 depicts our theoretical framework.

The need for exclusivity pertains to consumers' purchase of luxury brands to convey their identity and to distinguish themselves from others (Tian et al. 2001). Luxury brands, which are inherently scarce because of their price premium and restricted distribution, act as instruments to convey exclusivity (Bian and Forsythe 2012). In a similar vein, Cervellon and Shammas (2013) pointed out that luxury brand values are associated with status and the feeding one's ego. By contrast, sustainability represents inclusiveness, prudence, connectivity, security, and fairness (Gladwin et al. 1995). As such, sustainable firms incorporate social equity, economic efficiency, and environmental performance into their operational practices (Labuschagne et al. 2005). Consumers who pursue exclusivity purchase luxury products because not everyone has access to them; luxury is thus discriminatory, and its objective in democratic and open societies is to create social stratification
(Kapferer and Bastien 2012), which seems at odds with the notion of social equity and harmony. As a result, this type of consumer may not be as responsive to sustainable luxury products. Hence, our research hypothesizes that:

H1a Luxury consumers' need for exclusivity is negatively related to their purchase intentions towards sustainable luxury products.

Such a negative impact may be more salient in China than in the UK because of the higher power distance in the former. The concept of power distance refers to unequal and unfair distribution of power among society members (Hofstede 2007). It is also related to the existence and maintenance of a solid social stratum in a culture. Thus, individuals in high-power-distance culture believe that there are hierarchies and separations between socio-economic classes. In high-power-distance cultures, individuals are also more likely to believe in inequality and are highly motivated to attain and show an exclusive position in an organization or society. While buying and possessing status brands are ways to show their exclusivity in terms of higher position (Zhang and Kim 2013), a sustainable luxury brand that communicates equality and fairness may contradict such exclusivity. Concisely, in a high-powerdistance culture such as China, exclusivity is more closely linked to higher social status and inequality than is the case in low-power-distance cultures such as the UK, where seeking exclusivity will lead to less acceptance of sustainable luxury products. Thus, our research hypothesizes that:

H1b The negative relationship between luxury consumers' need for exclusivity and their purchase intentions towards sustainable luxury products is stronger in China than in the UK. 
The need for conformity is another motivation for luxury consumers. Some luxury consumers imitate the behaviour of a reference group or display collectivist behaviour in order to be identified as members of the group. The reference group exerts an influence over values, attitudes, aspirations, and norms of behaviour. Such influence also touches on the choice of symbols, which are transferred first to the product and then from the product to the consumer in creating self-concept.

Consumers have become increasingly concerned about social and environmental issues regardless of their social class. Consumer perceptions today depend not only on manufacturers' sustainability activities but also on how these companies engage in socially responsible behaviour with other stakeholders in the supply chain (SchrammKlein et al. 2016). A shift has occurred from 'conspicuous consumption' to 'conscientious consumption' (Cvijanovich 2011), in which high-end consumers act more responsibly in a socially and environmentally friendly manner. In support of this argument, research indicates that consumers are more concerned with brands perceived as ethical (Chun 2016). By openly purchasing sustainable luxury goods, consumers build an extension of themselves helping them identify with the desired reference group. In this way, purchasing sustainable luxury acts as a sign of prestige (Griskevicius et al. 2010) and an elite experience obtained from buying goods that are produced and traded conscientiously (Bendell and Kleanthous 2007). Thus, our research hypothesizes that:

H2a Luxury consumers' need for conformity is positively related to their purchase intentions towards sustainable luxury products.

The positive effect of the need to conform in purchasing sustainable luxury goods may be more salient in China than in the UK because China scores higher on collectivism. A consequence of collectivism is the pressure that groups exert to conform to social norms (Tse 1996). Research has shown that collectivist consumers are more likely to purchase products for reasons of group affiliation (Kacen and Lee 2002) or to fit in with the social norms (Wong and Ahuvia 1998). Prior studies also suggest that a luxury good is rarely purchased for its aesthetic characteristics in the Chinese environment. The purchase decision is almost always associated with the rich class in society and the symbolic elements of the good in the social context such as face-saving (public image) to enhance one's self-concept (Monkhouse et al. 2012; Zhan and He 2012). As such, we propose that the conformist motivation for consuming sustainable luxuries is more salient in China than in the UK. Thus, our research hypothesizes that:
H2b The positive relationship between luxury consumers' need for conformity and their purchase intentions towards sustainable luxury products is stronger in China than in the UK.

Personal value arises from the emotional value from luxury brands and is usually referred to as hedonic need. Hedonic need refers to the desire to experience positive feelings from consumption. Such positive emotional responses to luxury consumption have been linked to sensory pleasure, satisfaction, and aesthetics (Fauchois and Krieg 1991; Roux and Floch 1996; Vigneron and Johnson 2004). Seo and Buchanan-Oliver (2019) indicate that customers achieve this state when their consumption of luxury brands is based on joy, habits, and excitement. In fact, consumers were observed to be increasingly seeking hedonic value in luxury (Kapferer and Valette-Florence 2016).

At the same time, the hedonic dimension of luxury entails a psychological cost, in particular, the feeling of guilt. Consumers buying luxury items out of personal enjoyment (Vickers and Renand 2003) may have negative postpurchase emotions. For example, Cervellon and Shammas (2013) show that French and Italian consumers have higher feelings of guilt when they wear fur coats or buy expensive products. After the 2008 financial crisis, shoppers began suffering from 'luxury shame', with the financial crisis changing 'the guilty pleasure of shopping ... to plain old guilt' (Passariello 2009) and dampening consumption. However, if a luxury brand incorporates sustainable practices by either engaging in environmentally friendly ethical production or giving back to society, its products may provide a 'licensing effect' to consumers (Khan et al. 2010). They note that making an altruistic act such as a donation to charity helps establish a positive personal self-image and in turn liberates the person to make self-indulgent choices. Consumers could therefore compensate for the negative feelings associated with their own luxury purchases and achieve guilt-free enjoyment (Cervellon and Shammas 2013; Steinhart et al. 2013). Thus, our research hypothesizes that:

H3a Luxury consumers with high hedonic needs are more willing to choose sustainable luxury products.

The magnitude of guilt attached to luxury is dependent on culture (Cervellon and Carey 2011), particularly the culture dimension of indulgence (Hofstede 1984). Consumers in China do not place much emphasis on leisure time and control the gratification of their desires because China is a restrained society (Hofstede 1984). By contrast, in the UK, people generally exhibit a willingness to realize their impulses and desires with regard to enjoying life, having fun, and spending money. They place a higher degree of importance on personal pleasure and leisure time. Therefore, it is 
likely that the guilt associated with luxury consumption is stronger among Chinese consumers in comparison with UK consumers. In this way, a licensing effect tends to be more important for Chinese consumers than for UK consumers. In line with this rationale, Chinese luxury consumers driven by hedonic need might be more willing to choose sustainable luxury products over general luxury products than their UK counterparts. Thus, our research hypothesizes that:

H3b The positive relationship between luxury consumers' hedonic need and their purchase intentions towards sustainable luxury is stronger in China than in the UK.

Our theoretical model in Fig. 1 illustrates the six hypotheses on the relationship between luxury values and purchase intention towards sustainable luxury products with respect to the UK (Western context) and China (Eastern context).

\section{Methodology}

\section{Questionnaire design}

We employed a survey to collect data on sustainable luxury consumption. The survey contained questions about consumers' purchase of luxury products (e.g. purchase history, product category, brands, price range), their understanding of sustainable luxury, their perceived value from luxury products, their attitudes towards purchasing sustainable luxury products (vs. general luxury products), and their demographic information. The survey explained the research agenda so as to help respondents distinguish between intermediate and inaccessible luxury brand names, such as Chanel, Gucci, Burberry, Stella McCartney, Louis Vuitton, Valentino, Rolex, and Cartier, and accessible luxury brands, such as Ralph Lauren, DKNY, and Armani Exchange (De Barnier et al. 2012). We then asked respondents if they had ever purchased luxury products and to qualify their recent purchase in at least one of the product categories: footwear, jewellery, apparel, wristwatches, handbags, and accessories (e.g. scarfs, belts, ties, sunglasses) regardless if they were sustainable or not. ${ }^{1}$ This served as a filter question to target only meaningful samples - that is, actual purchasers of luxury items (Peterson 2001). The survey took place in China and in the UK, so we had both a Chinese and an English version of the questionnaire. We followed the commonly used translation and back-translation technique (Sperber et al.

\footnotetext{
1 According to D'Arpizio et al (2017), footwear, jewellery, and handbags ranked as the three fastest-growing product categories in 2017, increasing by, respectively, $10 \%, 10 \%$, and $7 \%$ that year. The bulk of global luxury purchases is for apparel, beauty, and handbags, with the value of $€ 61$ billion, $€ 54$ billion, and $€ 48$ billion, respectively.
}

1994) to ensure accuracy of the Chinese language translation. The questionnaire is provided in Appendix 1.

\section{Data collection}

Respondents in China and in the UK were recruited via the Qualtrics data service in January 2019. As women account for more than $65 \%$ share in the global luxury goods market (Research and Markets 2017), we applied quota sampling based on gender to ensure that the sample was proportionate to the number of men and women in the population of both countries (i.e. a ratio of four men to six women). We collected a total of 437 and 353 responses from China and the UK, respectively. However, some responses included inconsistent information such as featuring the purchase of a low-price Rolex watch and providing names that are not luxury brands. These were regarded and removed as invalid responses together with data points which indicated that respondents had purchased a luxury item more than two years ago. After further removing outliers and responses with missing data, we had 410 and 267 valid responses for China and the UK, respectively. Table 1 presents the demographic information of respondents in the two countries.

\section{Construct measurement and validity test}

Table 2 shows the four measures used in the study, namely the need for exclusivity, the need for conformity, hedonic need, and the purchase intention towards sustainable over general luxury products, as well as the associated questions derived from established scales. To keep the online survey at a reasonable length and yet satisfy the conditions for sufficient latent construct measurement (Kline 2005), we asked three or four questions from each established scale that measured the key constructs (Dodds et al. 1991; Wiedmann et al. 2009; Zhan and He 2012).

Exploratory factor analysis tested the convergent validity of the constructs. As Table 2 shows, all items were loaded significantly $(p<0.001)$ onto four corresponding factors (higher than 0.60), with Cronbach's alpha value for each construct above 0.70 (Moss et al. 1998). We also examined the internal validity of the measurement model through average variance extracted (AVE). All AVE values were within the acceptable threshold (values above 0.7 are considered good, while a value of 0.5 is acceptable) (Fornell and Larcker 1981). Therefore, the convergent validity of the constructs was established.

Discriminant validity is established when measures are not a reflection of some other variables. This can be indicated by low correlations between the measure of interest and the measures of other constructs (Cheung and Lee 2010). We conducted confirmatory factor analysis in IBM SPSS AMOS 25, a structural equation modelling (SEM) 
Table 1 Socio-demographic of respondents in China $(N=410)$ and the UK $(N=267)$

\begin{tabular}{|c|c|c|}
\hline & China $(\%)$ & $\mathrm{UK}(\%)$ \\
\hline \multicolumn{3}{|l|}{ Gender } \\
\hline Male & 39.4 & 43.4 \\
\hline Female & 60.6 & 56.6 \\
\hline \multicolumn{3}{|l|}{ Age } \\
\hline Under 20 years & 3.0 & 4.1 \\
\hline 21-29 years & 37.9 & 30.3 \\
\hline 30-39 years & 51.0 & 33.0 \\
\hline $40-49$ years & 7.9 & 18.0 \\
\hline $50-59$ years & 0.3 & 10.1 \\
\hline 60 years or over & 3.0 & 4.5 \\
\hline \multicolumn{3}{|l|}{ Employment status } \\
\hline Full-time employed & 91.8 & 67.0 \\
\hline Part-time employed & 2.0 & 13.9 \\
\hline Seeking work & 0.0 & 1.5 \\
\hline Retired & 0.0 & 2.3 \\
\hline Home duties & 0.7 & 9.0 \\
\hline Student & 5.2 & 4.1 \\
\hline Other & 0.3 & 2.3 \\
\hline \multicolumn{3}{|l|}{ Education } \\
\hline No qualification & 0.0 & 2.5 \\
\hline Year 10 or 12 certificate & 1.9 & 15.2 \\
\hline Trade certificate/vocational & 2.7 & 14.3 \\
\hline Certificate & 9.0 & 15.9 \\
\hline Diploma & 63.0 & 10.8 \\
\hline Bachelor's degree & 23.4 & 27.3 \\
\hline Postgraduate degree & 0.0 & 14.0 \\
\hline
\end{tabular}

software, and found that the AVE for each factor was larger than the square of the correlation estimates of the factor with all other constructs (Table 3, Panels A and B). We thus conclude that the measures show sufficient discriminant validity (Fornell and Larcker 1981). Taking all these indicators into account, our measurement model is satisfactory for both countries. Panels A and B in Table 4 show the descriptive statistics and correlation matrix for the UK and Chinese samples, respectively.

To minimize the effect of common method variance, we used several recommended procedural and statistical remedies (Podsakoff et al. 2003). We controlled for order bias by counterbalancing the order of the measurement of the variables. We changed the order of the scale items and the position of the predictor and criterion variables. We also conducted Harman's one-factor test with all the measurement items in a factor analysis without rotation and achieved a solution that accounted for $73.2 \%$ and $75.4 \%$ of the total variance, with the first factor accounting for $41.6 \%$ and $37.4 \%$ for the Chinese and UK samples, respectively. As a single dominant factor did not emerge for either sample, the common method bias is unlikely to be a concern in this study (Podsakoff and Organ 1986).

\section{Results}

\section{Luxury consumption habit}

In our sample, $93 \%$ of Chinese respondents and $77.14 \%$ of UK respondents have made their luxury purchase in the recent two years and the rest purchased the luxury items in the recent five or ten years. A simple comparison shows that Chinese consumers have purchased luxury items more frequently than UK consumers in the last two years, while UK consumers have been purchasers of luxury products for a longer period. Table 5 Panel A shows that luxury consumers in both China and the UK spent mostly on jewellery and handbags, although the percentage spending is higher in China. Respondents also indicated the price range of the luxury items they purchased (see Table 5 Panel B). A larger percentage of Chinese respondents spent more on expensive items (above USD 1000) than those in the UK. ${ }^{2}$ Taken together, our results offer support to the findings of D'Arpizio et al. (2017) that China is one of the fastest-growing countries for luxury goods.

\section{How do consumers understand sustainable luxury?}

Respondents were asked to choose five from a list of ten words to show their understanding of sustainable luxury. The top three words chosen by Chinese respondents were 'environmentally friendly', 'ethical', and 'durable', whereas UK respondents chose 'high quality', 'ethical', and 'environmentally friendly' as the top three words (see Fig. 2).

Respondents were also asked to indicate their perceived importance of several sustainable practices employed by luxury brands. The results show that the UK respondents were more concerned about the ethical treatment of workers and the use of child labour, while the Chinese respondents were more concerned with the protection of natural resources and working fairly with both customers and suppliers (see Fig. 3).

\footnotetext{
${ }^{2}$ Most luxury brands nominated by Chinese consumers are European based and purchasing such luxury products is more expensive in China than in the UK. However, the difference is not as huge particularly for those high-end brands (https://www.bragmybag.com/chane 1-bags-prices/).
} 
Table 2 Measures with reliability

\begin{tabular}{|c|c|c|c|}
\hline Variables & Items & Cronbach's $\alpha$ & AVE \\
\hline Need for exclusivity (Tian et al. 2001; Zhan and He 2012) & $\begin{array}{l}\text { 1. When a product I own becomes popular among the gen- } \\
\text { eral population, I begin to use it less } \\
\text { 2. I often try to avoid products or brands that I know are } \\
\text { bought by the general population } \\
\text { 3. Products don't seem to hold much value for me when } \\
\text { they are purchased regularly by everyone }\end{array}$ & 0.844 & 0.651 \\
\hline $\begin{array}{l}\text { Need for conformity (Bearden et al. 1989; Zhan and He } \\
\text { 2012) }\end{array}$ & $\begin{array}{l}\text { 1. When buying products, I generally purchase those brands } \\
\text { that I think others will approve of } \\
\text { 2. If I want to be like someone, I often try to buy the same } \\
\text { brands that they buy } \\
\text { 3. I often identify with other people by purchasing the same } \\
\text { products and brands they purchase }\end{array}$ & 0.873 & 0.582 \\
\hline Hedonic value (Wiedmann et al. 2009) & $\begin{array}{l}\text { 1. Luxury products should make me happy } \\
\text { 2. Luxury consumption should bring me self-satisfaction } \\
\text { 3. Luxury consumption can be a way to reduce stress } \\
\text { 4. Luxury products should make me feel better about myself }\end{array}$ & 0.879 & 0.603 \\
\hline $\begin{array}{l}\text { Purchase intention towards sustainable luxury products } \\
\text { (adapted from Dodds et al. 1991) }\end{array}$ & $\begin{array}{l}\text { 1. I prefer a sustainable luxury item than a general luxury } \\
\text { item } \\
\text { 2. My willingness to buy a luxury item will be high if it has } \\
\text { sustainable features } \\
\text { 3. If I were going to purchase a luxury product, I would } \\
\text { consider buying a luxury brand with sustainable policy }\end{array}$ & 0.851 & 0.656 \\
\hline
\end{tabular}

Table 3 Measurement results: AVE and SIC

\begin{tabular}{lllll}
\hline & PISL & NFE & NFC & HV \\
\hline A: $U K$ & & & & \\
PISL & $0.662^{\mathrm{a}}$ & & & \\
NFE & $0.012^{\mathrm{b}}$ & 0.652 & & \\
NFC & 0.003 & 0.267 & 0.557 & \\
HV & 0.054 & 0.144 & 0.278 & 0.653 \\
B. China & & & & \\
PISL & $0.656^{\mathrm{a}}$ & & & \\
NFE & $0.154^{\mathrm{b}}$ & 0.648 & & \\
NFC & 0.264 & 0.554 & 0.566 & \\
HV & 0.466 & 0.425 & 0.448 & 0.672 \\
\hline
\end{tabular}

$N F E$ need for exclusivity, $N F C$ need for conformity, $H N$ hedonic need, and PISL purchase intention towards sustainable over general products

${ }^{a}$ Diagonal entries represent the AVE by the construct

${ }^{\mathrm{b}}$ Off-diagonal entries represent the squared inter-construct correlation (SIC)

\section{How do consumers perceive the sustainability of luxury brands?}

Each respondent was asked to nominate a brand from the product category that they have purchased. Respondents from China nominated 59 distinct brands in total, and UK respondents nominated 93 brands. Among those brands, 42 brands nominated by Chinese respondents and 40 brands nominated by UK respondents fell in the Global Power of Luxury Goods List 2017 (Deloitte 2017). Table 6 shows the top 10 nominated luxury brands by the respondents from both countries.

When respondents were asked to reflect whether they believed their nominated luxury brand employed sustainable practices, $73.67 \%$ of Chinese respondents agreed that the luxury brand they consume is sustainable, while only $48.57 \%$ of UK respondents agreed to this. Such results suggest that UK consumers seem to be more critical of whether their nominated luxury brand employs sustainable practices.

\section{Structural equation modelling analysis}

We tested the model presented in Fig. 1 using AMOS 25 with maximum likelihood estimation. The sample size of 410 Chinese consumers and 267 UK consumers with 14 indicators in the model was sufficiently large, given that the suggested sample size for structural equation models should be at least 200 (Kline 2005) or 10 observations per indicator variable (Nunnally 1978). To test the hypotheses, we first ran a multi-group analysis and found that at least one path parameter differed between the Chinese and UK samples. (More details of multi-group analysis using SEM are provided in Appendix 2.) Therefore, we adopted the unconstrained models, which allowed path parameters to be estimated separately for the two samples. Table 7 shows the results of the unconstrained structural equation models. 


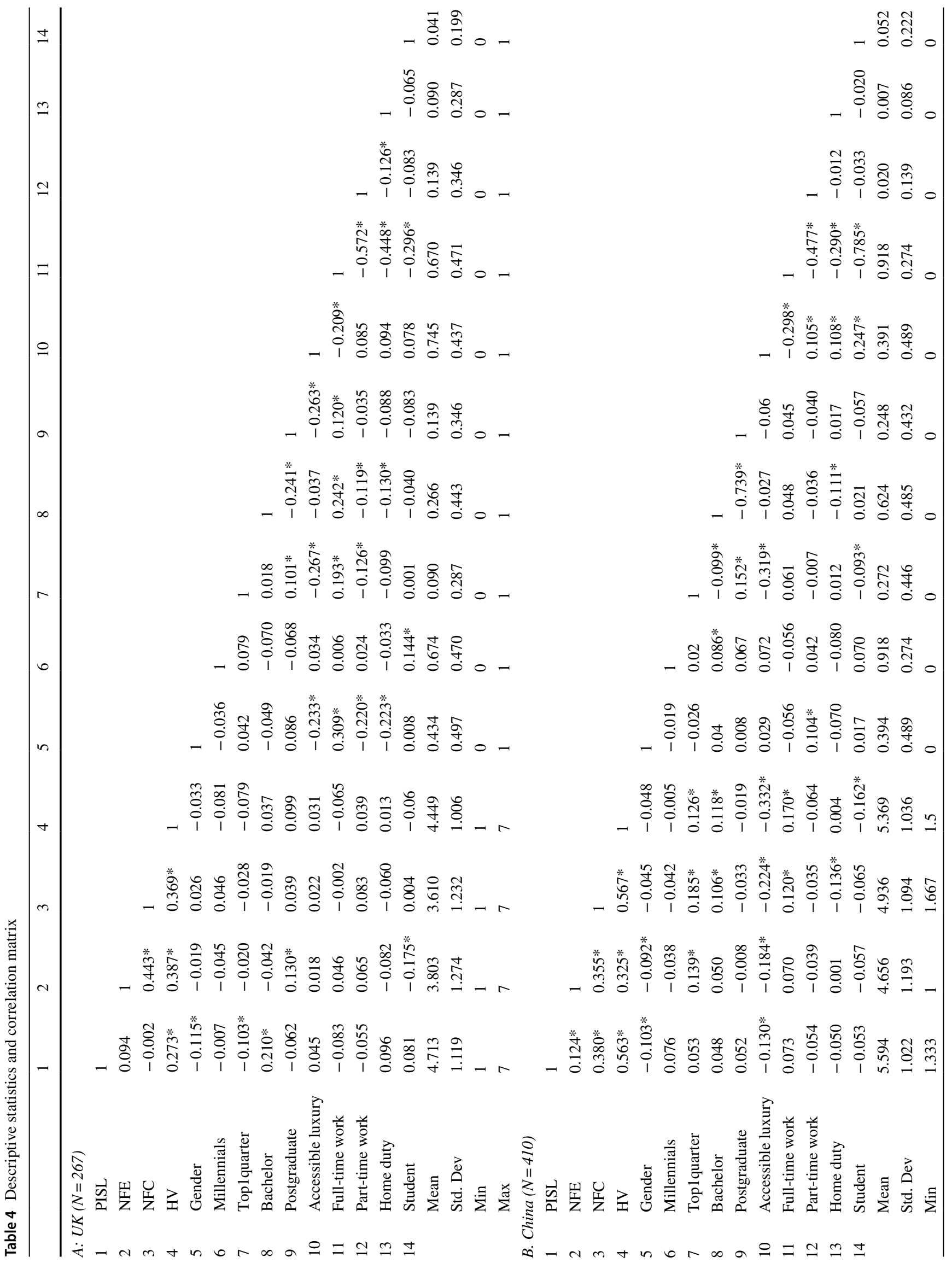

承 


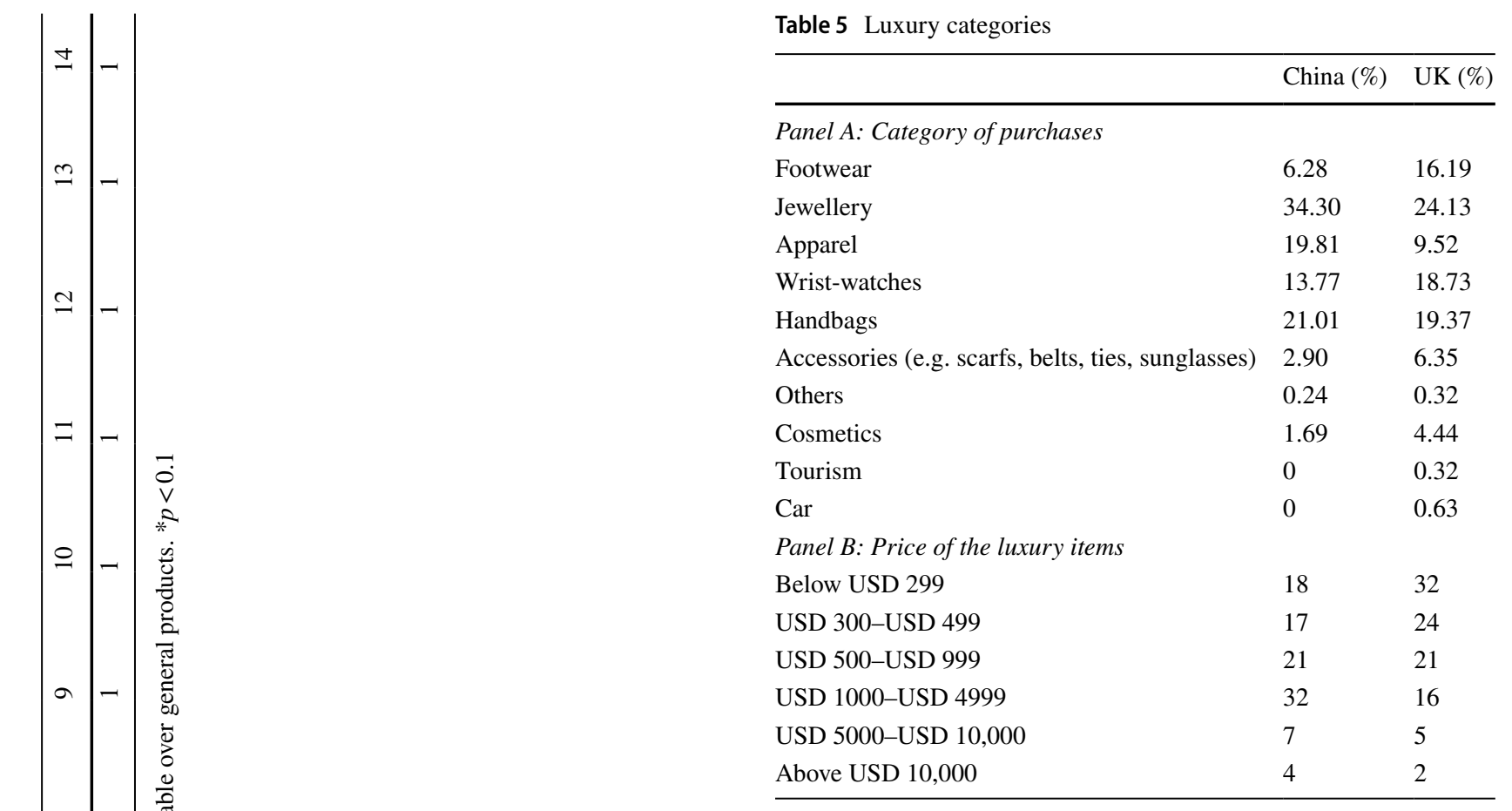

Because the minimum fit of the chi-square was non-significant $(p>0.1$; Tucker-Lewis Index, Comparative Fit Index, Normed Fit Index, and Incremental Fit Index were all above 0.95, while RMSEA (root-mean-square error approximation) was below 0.05), the models had a good fit in both samples.

The multi-group analysis reported the matrix of critical ratios for path parameter differences between the unconstrained Chinese and UK models. The $z$ test critical value greater than 11.961 in a two-tailed test indicated that the difference between the two groups was statistically significant at $5 \%$.

As Table 7 shows, the need for exclusivity is negatively related to higher purchase intentions towards sustainable luxury over general luxury products in the Chinese sample $(\beta=-0.109 ; p<0.05)$, but the result is positively significant in the UK sample $(\beta=0.231 ; p>0.05)$. The $z$-statistic of 2.859 suggests that the need for exclusivity differs significantly between China and the UK. The negative and significant relationship in China could be due to the high-powerdistance culture, implying that Chinese luxury consumers who are more motivated to show their exclusive position do not associate sustainable luxury items with exclusivity and hence have lower purchase intention. In contrast, UK consumers seeking exclusivity have higher purchase intentions. The results lend support to H1b.

The need for conformity is positively but not significantly related to higher purchase intentions towards sustainable luxury over general luxury products in the Chinese sample $(\beta=0.012 ; p>0.1)$. In contrast, the UK results show a significant and negative relationship $(\beta=-0.282$; 


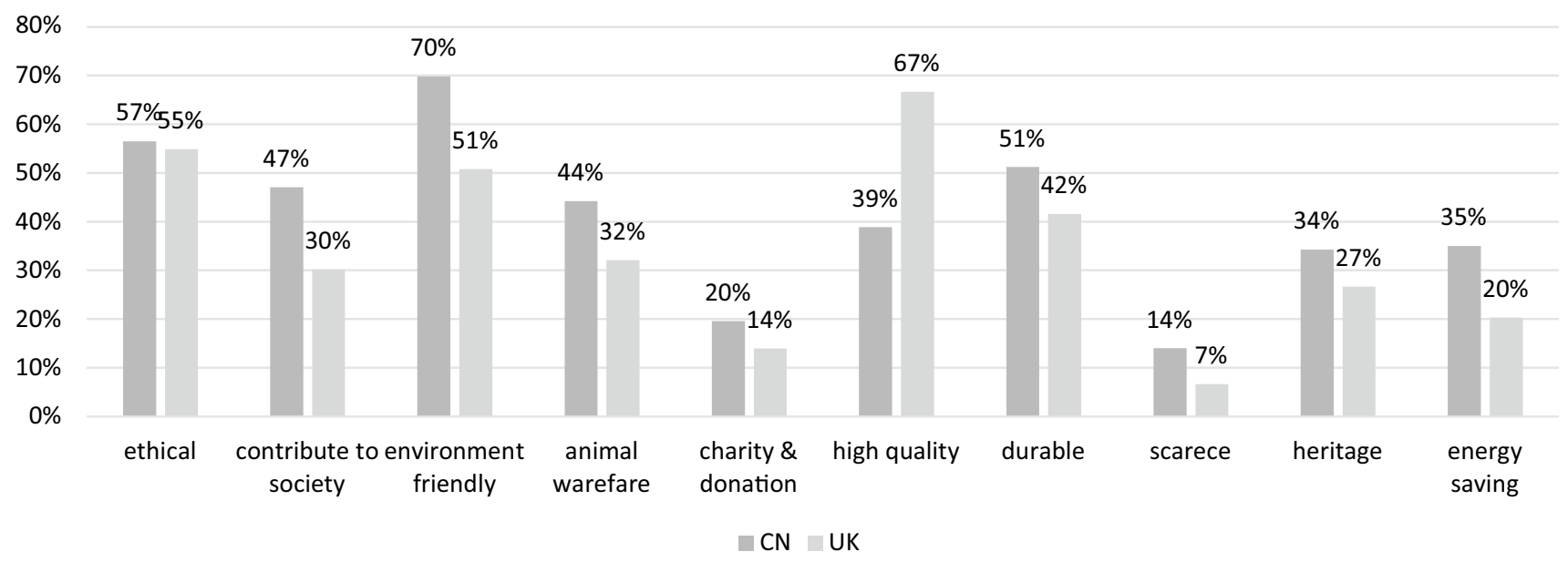

Fig. 2 What does sustainable luxury mean?

5.800

5.714

5.700

5.597

5.600

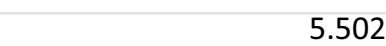

5.500

5.400

5.374

5.300

5.200

5.100

5.000

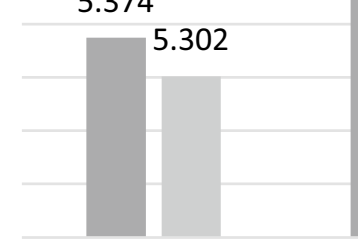

5.502

5.432

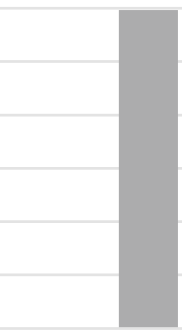

not waste

protect

resources endangered

work fairly with

customers and

suppliers
5.495

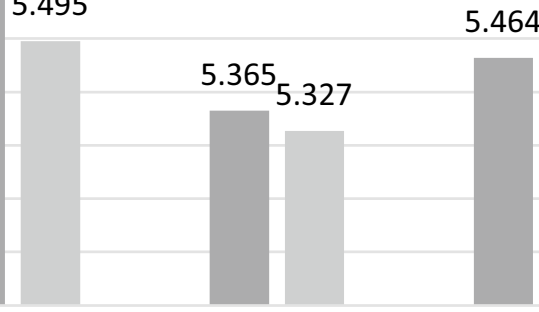

5.464

\section{contribute to community welfare}

5.587

China U.K.

Fig. 3 Which sustainable practices matter?

$p<0.01$ ), suggesting that UK luxury consumers are unlikely to purchase sustainable luxury due to social mimetic pressure. The $z$-statistic of 2.486 suggests that the effects differ significantly between China and the UK. Thus, H2b is not supported.

The hedonic need is positively and significantly related to higher purchase intentions towards sustainable luxury over general luxury products in both samples (China: $\beta=0.693$, $p<0.001$; UK: $\beta=0.240, p<0.01)$. The $z$-statistic of -3.890 suggests that the effect is significantly stronger in China than in the UK. Thus, H3b is well supported suggesting that sustainable features of luxury products are more salient in motivating hedonism-driven luxury consumption in China than in the UK.

We further conducted a simple linear regression model using our main variables and other control variables in the analysis, to test the hypotheses $\mathrm{H} 1 \mathrm{a}, \mathrm{H} 2 \mathrm{a}$, and $\mathrm{H} 3 \mathrm{a}$ as well as to check the robustness of our results while ruling out the influence of other factors using the following model. ${ }^{3}$

\footnotetext{
${ }^{3}$ Although SEM allows us to test the interaction and total effect of all main variables in our hypotheses, SEM has some limitations. First, in addition to the main consumption variables, there are other control variables that could affect consumers' purchase intention for sustainable luxury items. When using SEM, it is ideal to always include all the control variables. However, these control variables will count against the sample size calculations. The more controls to be included in SEM, the larger the sample size needs to be. Considering the sample size, we only included the main instruments and one control variable (education, treated as interval data with 7 levels) in SEM. Second, several of our control variables are dummy variables, such as (i) gender, (ii) occupation categories, (iii) accessible or non-accessible luxury, etc. Dummy variables are not continuous and do not have normal distributions, hence violating several important assumptions in SEM. In addition, including those dummy variables will also empiri-
} 
Table 6 Top 10 nominated luxury brands: are they sustainable?

\begin{tabular}{|c|c|c|c|c|c|c|c|c|c|}
\hline \multicolumn{5}{|c|}{ China } & & \multicolumn{4}{|l|}{ UK } \\
\hline & Nominated brand (\%) & Sustainable (\%) & Not sure $(\%)$ & $\begin{array}{l}\text { Not sus- } \\
\text { tainable } \\
(\%)\end{array}$ & & Nominated brand (\%) & Sustainable (\%) & Not sure $(\%)$ & $\begin{array}{l}\text { Not sus- } \\
\text { tainable } \\
(\%)\end{array}$ \\
\hline 1 & Chanel (16.6\%) & 65.4 & 30.8 & 3.8 & 1 & Gucci $(14.0 \%)$ & 43.2 & 38.6 & 18.2 \\
\hline 2 & LV (15.4\%) & 78.3 & 15.0 & 6.7 & 2 & Michael Kors (6.1\%) & 57.9 & 26.3 & 15.8 \\
\hline 3 & Gucci $(12.5 \%)$ & 75.5 & 18.4 & 6.1 & 3 & Rolex $(5.7 \%)$ & 61.1 & 22.2 & 16.7 \\
\hline 4 & Cartier (7.2\%) & 89.7 & 10.3 & 0.0 & 4 & Pandora (4.8\%) & 53.3 & 33.3 & 13.3 \\
\hline 5 & Dior $(4.1 \%)$ & 86.7 & 13.3 & 0.0 & 5 & Nike $(4.5 \%)$ & 71.4 & 7.1 & 21.4 \\
\hline 5 & Tiffany $(4.1 \%)$ & 76.5 & 17.7 & 5.9 & 6 & Chanel (4.1\%) & 46.2 & 38.5 & 15.4 \\
\hline 7 & Nike $(3.6 \%)$ & 60.0 & 26.7 & 13.3 & 7 & Armani $(3.5 \%)$ & 27.3 & 72.7 & 0.0 \\
\hline 7 & Armani (3.6\%) & 93.3 & 0.0 & 6.7 & 7 & Ralph Lauren (3.5\%) & 45.5 & 45.5 & 9.1 \\
\hline 9 & Rolex $(2.9 \%)$ & 90.9 & 9.1 & 0.0 & 9 & Tiffany $(3.2 \%)$ & 50.0 & 50.0 & 0.0 \\
\hline 9 & Rolex $(2.9 \%)$ & 90.9 & 9.1 & 0.0 & 9 & Burberry $(2.25 \%)$ & 28.6 & 71.4 & 0.0 \\
\hline 9 & Hermès (2.9\%) & 90.0 & 10.0 & 0.0 & 10 & LV (2.2\%) & 28.6 & 57.1 & 14.3 \\
\hline
\end{tabular}

The percentage in parentheses is the percentage of respondents nominating the specific brand

Table 7 Model coefficients and goodness-of-fit SEM estimation

\begin{tabular}{lllc}
\hline & China & UK & $\begin{array}{l}\text { Z-stat. of difference in coef- } \\
\text { ficients between the two } \\
\text { samples }\end{array}$ \\
\hline NFE (need for exclusivity) & $-0.109^{*}(0.048)$ & $0.231^{*}(0.109)$ & 2.859 \\
NFC (need for conformity) & $0.012(0.074)$ & $-0.282^{* *}(0.092)$ & -2.486 \\
HV (hedonic value) & $0.693^{* * *}(0.083)$ & $0.240^{* *}(0.081)$ & -3.890 \\
Education level & $5.740 *(2.411)$ & $11.449(18.199)$ & 0.311 \\
Goodness-of-fit index & & & \\
$\chi^{2}, p$ value & $147.277,0.059$ & $69.871,0.204$ & \\
TLI & 0.990 & 0.989 & \\
IFI & 0.993 & 0.993 & \\
NFI & 0.962 & 0.947 & \\
GFI & 0.971 & 0.965 & \\
AGFI & 0.949 & 0.939 & \\
CFI & 0.993 & 0.993 & \\
RMSEA & 0.018 & 0.023 & \\
CMIN/DF & 1.207 & 1.145 & \\
Sample size & 410 & 267 & \\
\hline
\end{tabular}

Unstandardized coefficients are reported with standard errors in parentheses. A $z$-stat. greater than 1.96 indicates that the difference in coefficients between the two samples was significant at $5 \%$

$* * * p<0.001 ; * * p<0.01 ; * p<0.05 ;+p<0.1$

\section{Footnote 3 (continued)}

cally overwhelm the model, given that several dummies have to be included to represent different categories (Ping, 2010). Due to these reasons, we did not include all the control variables in the SEM. The results of our main variables, though significant, only account for a small amount of the variance in the dependent variables. To provide more robust results of our main variables, we further used simple linear regression model, in which the Ordinary Least Squares (OLS) procedure was used. The simple linear regression model allows to control more variables that could affect purchase intention.
Purchase intention $=\mathrm{NFE}+\mathrm{NFC}+\mathrm{HV}+\mathrm{NFE}^{\prime}$ China

$$
+\mathrm{NFC}^{\prime} \text { China }+\mathrm{HV}^{\prime} \text { China }+ \text { control variables }
$$

Factors that could influence luxury consumers' purchase intention of sustainable luxury products are included as the control variables. The coding of control variables is presented in Table 8 under Note (3). Table 8 shows the four models employed in the simple linear regression. Model 1 tests hypotheses $\mathrm{H} 1 \mathrm{a}, \mathrm{H} 2 \mathrm{a}$, and $\mathrm{H} 3 \mathrm{a}$ using the full sample. Results from model 1 only support $\mathrm{H} 3 \mathrm{a}$, which predicts a 
Table 8 Simple linear regression results

\begin{tabular}{|c|c|c|c|c|}
\hline & $\begin{array}{l}\text { Model } 1 \\
\text { Full sample }\end{array}$ & $\begin{array}{l}\text { Model } 2 \\
\text { China sample }\end{array}$ & $\begin{array}{l}\text { Model } 3 \\
\text { UK sample }\end{array}$ & $\begin{array}{l}\text { Model } 4 \\
\text { Full sample }\end{array}$ \\
\hline $\mathrm{NFE} \times$ China & & & & $-0.11+(0.07)$ \\
\hline $\mathrm{NFC} \times$ China & & & & $0.22 * *(0.08)$ \\
\hline $\mathrm{HV} \times$ China & & & & $0.21 *(0.09)$ \\
\hline China & $0.34 * *(0.10)$ & & & $-1.1 * *(0.40)$ \\
\hline NFE & $-0.05(0.03)$ & $-0.07+(0.04)$ & $0.06(0.06)$ & $0.04(0.05)$ \\
\hline NFC & $0.02(0.04)$ & $0.11 *(0.05)$ & $-0.11+(0.06)$ & $-0.10+(0.05)$ \\
\hline $\mathrm{HV}$ & $0.46^{* * *}(0.04)$ & $0.54 * * *(0.05)$ & $0.31 * * *(0.07)$ & $0.31 * * *(0.06)$ \\
\hline Gender & $-0.19 *(0.08)$ & $-0.19 *(0.09)$ & $-0.16(0.14)$ & $-0.18 *(0.07)$ \\
\hline Part-time employed & $-0.16(0.16)$ & $-0.08(0.30)$ & $-0.1(0.20)$ & $-0.13(0.15)$ \\
\hline Seeking work & $0.22(0.48)$ & & $0.16(0.54)$ & $0.1(0.48)$ \\
\hline Retired & $0.74+(0.40)$ & & $0.76+(0.45)$ & $0.76+(0.40)$ \\
\hline Home duties & $0.26(0.20)$ & $-0.47(0.50)$ & $0.42+(0.25)$ & $0.28(0.2)$ \\
\hline Student & $0.25(0.18)$ & $0.12(0.19)$ & $0.69 *(0.34)$ & $0.3+(0.18)$ \\
\hline Other & $-0.04(0.36)$ & $1.9 *(0.84)$ & $-0.14(0.44)$ & $0.04(0.36)$ \\
\hline Top $1 / 4$ income bracket & $-0.06(0.10)$ & $-0.06(0.10)$ & $-0.32(0.24)$ & $-0.09(0.10)$ \\
\hline Bachelor's degree & $0.29 * *(0.10)$ & $0.09(0.13)$ & $0.56 * *(0.16)$ & $0.29 * *(0.10)$ \\
\hline Postgraduate degree & $0.24 *(0.12)$ & $0.23(0.15)$ & $-0.01(0.21)$ & $0.26 *(0.11)$ \\
\hline Millennials ( $<40$ years old) & $0.14(0.10)$ & $0.22(0.16)$ & $0.11(0.14)$ & $0.14(0.10)$ \\
\hline Accessible (<USD1000) & $0.02(0.09)$ & $0.11(0.10)$ & $-0.05(0.16)$ & $0.07(0.09)$ \\
\hline Constant & $2.62 * * *(0.23)$ & $2.24 * * *(0.32)$ & $3.35 * * *(0.38)$ & $3.36 * * *(0.3)$ \\
\hline F & $20.93 * * *(16)$ & $16.96 * * *(13)$ & $3.64 * * *(15)$ & $19.35 * * *(19)$ \\
\hline$R^{2}$ & 0.339 & 0.361 & 0.179 & 0.361 \\
\hline $\operatorname{Adj} R^{2}$ & 0.323 & 0.340 & 0.130 & 0.342 \\
\hline Sample size & 677 & 410 & 267 & 677 \\
\hline
\end{tabular}

(1) Standard errors are in parentheses. *** $p<0.001 ; * * p<0.01$; $* p<0.05 ;+p<0.1$

(2) Main variable: $\mathrm{NFE}=$ need for exclusivity, NFC need for conformity, $\mathrm{HN}=$ hedonic need, and $\mathrm{PISL}=$ purchase intention towards sustainable over general products

(3) Other than the main variables used, we included several control variables: (1) gender $(1=$ male, $0=$ female); (2) employment status (7 dummy variables for full-time employed (reference category), parttime employed, seeking work, retired, home duties, student, others); (3) income level (1 if the respondent is in the top one-quarter income bracket and 0 otherwise); (4) education level (3 dummies for below degree, degree, and postgraduate qualifications, with below degree as the reference category); and (5) age ( 1 for $<40$ years and 0 otherwise). We also categorized the luxury product a respondent spent most on into two categories: <USD 1000 (accessible luxury) and those priced at USD 1000 or above (intermediate and inaccessible luxury as reference category). In the result table, coefficients of reference categories are not shown. (6) China is a dummy variable coded as 1 if the respondent is from China and 0 otherwise. The correlation matrix in Table 4 shows that none of the variables entering into our regression are highly correlated. The variance inflation factor (VIF) of the whole regression model is only 4.40, lower than 5 (the rules of thumb for serious multicollinearity) (O'brien 2007)

(4) The coefficients for seeking work and retired category in Chinese sample are not available because none of the respondents fall into these two employment categories in our Chinese sample

general positive relationship between hedonic needs and purchase intention of luxury items over general items $(\beta=0.46$; $p<0.01)$. H1a and $\mathrm{H} 2 \mathrm{a}$ are not supported given that the need for exclusivity and need for conformity do not show significant results $(\beta=-0.05 ; p>0.1 ; \beta=0.02 ; p>0.1)$. Such results suggest that the traditional luxury values such as seeking exclusivity and conformity from luxury purchase cannot predict purchase intention for sustainable luxury generally.
Models 2 and 3 test hypotheses H1b, H2b, and H3b using the China and UK sample(s), respectively. Model 4 tests the differences across China and the UK by incorporating interactions between China and the main variables (NFE, NFC, and HV). Significant coefficients for the interaction between China and NFE, NFC, and HV would suggest that the influence of the luxury values differs significantly between China and the UK. The results in Models 2, 3, and 4 in Table 8 are generally consistent with those from SEM, supporting $\mathrm{H} 1 \mathrm{~b}$ and $\mathrm{H} 3 \mathrm{~b}$. One notable result from the linear regression 
Table 9 Summary of results

\begin{tabular}{|c|c|c|c|c|c|c|c|}
\hline & \multicolumn{3}{|c|}{ Structural equation model } & \multicolumn{2}{|c|}{ Linear regression model } & \multirow{2}{*}{\multicolumn{2}{|c|}{$\begin{array}{l}\text { Linear regression model } \\
\text { Full sample }\end{array}$}} \\
\hline & China & UK & & China & UK & & \\
\hline $\begin{array}{l}\text { H1a: Luxury consumers' need for exclusiv- } \\
\text { ity is negatively related to their purchase } \\
\text { intentions towards sustainable luxury } \\
\text { products }\end{array}$ & & & & & & -0.050 & Not supported \\
\hline $\begin{array}{l}H 1 b \text { : The negative relationship between } \\
\text { luxury consumers' need for exclusivity } \\
\text { and their purchase intentions towards } \\
\text { sustainable luxury products is stronger in } \\
\text { China than in the UK }\end{array}$ & $-0.109^{*}$ & $0.231 *$ & Supported & $-0.070+$ & Supported & & \\
\hline $\begin{array}{l}H 2 a \text { : Luxury consumers' need for } \\
\text { conformity is positively related to their } \\
\text { purchase intentions towards sustainable } \\
\text { luxury products }\end{array}$ & & & & & & 0.020 & Not supported \\
\hline $\begin{array}{l}H 2 b \text { : The positive relationship between } \\
\text { luxury consumers' need for conformity } \\
\text { and their purchase intentions towards } \\
\text { sustainable luxury products is stronger in } \\
\text { China than in the UK }\end{array}$ & 0.012 & $-0.282 * *$ & Not supported & $0.110 * *$ & $-0.110+$ Supported & & \\
\hline $\begin{array}{l}H 3 a \text { : Luxury consumers with high hedonic } \\
\text { needs are more willing to choose sustain- } \\
\text { able luxury products }\end{array}$ & & & & & & $0.460 * *$ & Supported \\
\hline $\begin{array}{l}H 3 b \text { : The positive relationship between } \\
\text { luxury consumers' hedonic need and } \\
\text { their purchase intentions towards sustain- } \\
\text { able luxury is stronger in China than in } \\
\text { the UK }\end{array}$ & $0.693 * * *$ & $0.240 * *$ & Supported & $0.540^{*}$ & $0.310 * * *$ Supported & & \\
\hline
\end{tabular}

models is that the relationship between the need for conformity and purchase intention towards sustainable luxury products is positive for Chinese consumers $(\beta=0.11 ; p<0.01)$, but negative for UK consumers $(\beta=-0.11 ; p<0.1)$, thus supporting $\mathrm{H} 2 \mathrm{~b}$. Table 9 summarizes the results from both the SEM and linear regression models.

\section{Discussion}

Research suggests that luxury brands' incorporation of sustainable development can enhance brand differentiation and companies' sustainability image (Kim and Ko 2012). However, studies also show that consumers do not put much value on luxury brands' sustainable efforts (Bhattacharya and Sen 2004; Ehrich and Irwin 2005). This poses a problem: if consumers do not appreciate sustainable practices of luxury brands, luxury brands' investment in various sustainable practices will eventually become an extra cost without payback, threatening their bottom lines (Johnston et al. 2019). Our research has attempted to address this issue in a cross-cultural context.

The empirical results reveal that consumers' understanding of 'sustainable luxury' leans towards the concept of sustainability rather than the concept of luxury. For example, while previous studies suggest that scarcity is an important component in luxury items (Dubois and Paternault 1995; Janssen et al. 2014), our study indicates that only $14 \%$ of Chinese respondents and $7 \%$ of UK respondents chose scarcity as a keyword when asked to indicate their understanding of sustainable luxury. This result also suggests that when sustainability is attached to a luxury product, the value stemming from being scarce could be attenuated. Such a result aligns with prior research. For example, Achabou and Dekhili (2013) demonstrated that regular luxury buyers are against purchasing a Hermès product made of recycled cotton because they believe recycling means that the product is not rare and precious and therefore considered not prestigious. This implies that when the sustainable concept is highlighted for a luxury product, it negates some of the commonly held luxury consumption values/needs.

At the same time, prior studies suggest that luxury consumers are not explicitly interested in sustainability criteria when purchasing luxury brands, but they nevertheless have strong expectations (Gardetti and Torres 2013). Our results corroborate this finding and show that $73.67 \%$ of Chinese consumers believe that the luxury brands they purchased are sustainable. However, this applies to only $48.57 \%$ of UK consumers. Among the top 10 luxury brands purchased by our Chinese respondents, consumers 
overwhelmingly believed that these brands are sustainable. In the UK, many respondents remained neutral. For example, the Armani brand which enjoys a high prestige has $93.3 \%$ of Chinese respondents believing it to be sustainable. However, only $27.3 \%$ of respondents in the UK believed so, while $72.7 \%$ were unsure. This result stems from a halo effect of the luxury brand, in which raters allow overall or trait impressions to affect the evaluation of other traits of the rate (Oh and Ramaprasad 2003). In this case, it seems that a majority of Chinese luxury consumers implicitly hold the belief that luxury brands have a duty to be sustainable, a mission of exemplarity based on their price and promised exceptional quality. Our findings also show that such a halo effect is more salient among Chinese than UK consumers. This is understandable for a less mature luxury market, in which consumers still lack a good understanding of the history, culture, and style related to a luxury brand (Rovai 2016).

In line with the positive perception among Chinese respondents of the sustainability level in luxury brands, their purchase intentions towards sustainable luxury over general luxury are significantly higher than their UK counterparts (5.41 vs. $4.97, p<0.001)$. Overall, they believe that luxury brands have a societal responsibility to enhance environmental sustainability, ensure animal welfare, and conserve resources. Such outcomes bring caution to the luxury sector in China, suggesting that sustainability is deemed an implicit requirement, more than ever before. There could be a high risk for brands that ignore these requirements, all the more in a context in which they are increasingly subjected to criticism because of their visibility. The halo effect could easily turn into the horn effect, in which consumers' perceptions of a luxury brand are unduly influenced by a single unsustainable practice or incident. For some brands, it is becoming urgent to bridge the gap between expectations and reality to preserve their reputation or even to maintain their licence to operate, particularly in China. By contrast, UK consumers seem more suspicious of luxury brands' sustainable gestures, even though they still purchase the products.

We also examined three commonly held social and personal values of luxury consumers in China and in the UK. Hennigs et al. (2012) showed that the basic motivational drivers of luxury consumers (i.e. financial, functional, personal, and social) are similar among these dimensions of luxury value perceptions. However, the relative importance of these dimensions varies. For example, Rovai (2016) posited that social value plays a more important role in influencing Eastern consumers' luxury purchase, while personal values are more important motivators for Western luxury consumers. Our structural equation model and regression analyses provided further evidence of how these commonly held values align with or contradict the sustainable luxury concept in different ways in China and in the UK.
We found that the need for exclusivity discourages Chinese consumers from choosing sustainable luxury products over general luxury products, but the need for exclusivity encourages UK consumers to do so. We attribute this to the different connotations of exclusivity in China and the UK. In China, exclusivity seems to be more about social status arising from inequality and stratification (Rovai 2016); sustainable luxury does not align with such exclusivity. This is also consistent with prior research. For instance, Torelli et al. (2012) showed that consumers value luxury brands engaging in sustainability less because it reduced their perceptions of exclusivity associated with the brand. We do not observe such a negative effect in the UK where low power distance does not result in as much contradiction between sustainability and exclusivity as that of China. On the contrary, UK consumers seeking exclusivity look towards luxury products that are unique and different from others and luxury products with sustainable features might be perceived as such.

For Chinese consumers, purchasing sustainable luxury is also driven by their intention to benchmark the expected social trend so as to show their affiliation with a desired social group. Sustainable consumption has not been embraced by most consumers traditionally in China. In recent years, however, sustainable consumption behaviour has increased in China, especially in urban cities (Shao 2019). Sustainable production and consumption are part of China's national strategy in its 13th Five-Year Plan (2016-20). Correspondingly, some clear evidence of consumers' adoption of sustainable consumption can be seen in food purchasing behaviour (Yin and Cao 2012; Yin et al. 2013). A report released by the China Chain Store and Franchise Association indicates that more than 70 percent of respondents were willing to pay 10 percent more for sustainable products or services over non-sustainable ones (China Daily 2017). Alibaba's research arm further finds that $16.2 \%$ of the consumers on Alibaba's China retail marketplaces bought five or more green products in 2015 and were willing to pay an average of $33 \%$ more for sustainable products (Lee 2020). All of the evidence suggests that sustainable consumption is a new trend among Chinese consumers, particularly in urban cities. Such a new trend facilitates luxury consumers' buy-in of sustainable luxury items due to their pursuit of social desirability through expressing social responsibility. In contrast, UK consumers pursue more idiosyncratic choices without much restriction to conform to an external expectation. They are instead more individualistic and discerning, and perhaps more critical towards being a trend follower. Such results can be supported by our descriptive data, which show that more than half of UK respondents do not agree that the luxury brand they consume is sustainable.

Our results suggest that hedonic need generally drives consumers' purchase intentions towards sustainable luxury. Athwal et al. (2019) noted inconsistencies in the literature 
on the fit between hedonism and sustainable luxury. On the one hand, a consumer may see sustainability as utilitarian and luxury as hedonic (Steinhart et al. 2013). On the other hand, Cervellon and Shammas (2013) suggest that hedonism is part of sustainable luxury and a major added value of sustainable products. Our result lends support to a fit between hedonic need and sustainability component of luxury. We attribute such a fit to the guilt-free licence provided by sustainable luxury. Such an explanation is further strengthened by our results, indicating a stronger positive relationship between hedonic need and the purchase intention of sustainable luxury in China and the UK. Having sustainable features in luxury products help alleviate the tension between modern Chinese consumers' pursuit of hedonism and traditional Chinese virtues. Adams (2011) suggests that modern Chinese consumers appreciate hedonic and utilitarian features in luxury goods similar to consumers in the USA. This may be due to the dynamic economic changes taking place in China with the country becoming more individualistic as a result of print media, social media, advertising, and other commercial influences (Zhou and Hui 2003; Zhang and Harwood 2004). At the same time, the classic virtue of thrift in Chinese culture acts as a restraint on consumerist hedonic values (Faure and Fang 2008; Wang and Lin 2009). Sustainable features in luxury items thus act as a licence for Chinese consumers to justify luxury consumption. In comparison, consumers from the UK feel less guilty from luxury consumption due to their high indulgence culture resulting in less guilt-free pleasure from sustainable luxury.

Finally, our results suggest that the coefficient of hedonic need is far greater than those of exclusivity and conformity in both China and the UK. This aligns with prior studies that luxury consumption has undergone a major transformation due to changes in societal values since the 1990s (Gobe 2003), and increasingly, more consumers are turning to emotive needs when purchasing luxury items than functional and social needs (Kapferer and Valette-Florence 2016). This result also implies that consumers perceive the benefits of sustainable luxury mainly from emotions, thereby evoking guilt-free joy. For the consumers, doing good and no harm, and contributing to society cumulatively free them from feeling guilty when making unnecessary and expensive purchases.

\section{Contributions}

First, this study extends our understanding of value perceptions pertaining to sustainable luxury product consumption and thereby contributing to the theorizing of sustainable luxury research. While the current literature on sustainable products is rich, they are limited to research on commoditized cotton, coffee, or paper/pulp/wood products (Auger et al. 2003, 2008). Some studies disaggregate the concept of sustainability into sub-components to show a possible fit, albeit with limited observations (Cervellon and Shammas 2013; Janssen et al. 2014). Our study empirically demonstrates how three commonly held luxury values influence consumers' preferences for sustainable luxury products. Our study deepens scholarly understanding of whether luxury and sustainability are compatible, and also answers the calls of Tynan et al. (2010) and Shukla (2011) for the empirical testing of value perceptions. This study provides rigorous empirical testing of value perceptions, augmenting the validity and reliability of the extant theory and literature on luxury consumption.

Second, this study provides cross-cultural insights into sustainable luxury by comparing China and the UK-two major luxury markets with different economic developmental trajectories and cultural characteristics. Prior studies show that consumers across cultures may have similar motivations when purchasing luxury goods (Hennigs et al. 2012), but the salience of their effects may vary across different cultures. Our study reveals that hedonic needs constitute an important global driver for consumers when purchasing sustainable luxury products, but its impact is more prominent in China than in the UK. The results also show that the effects of the needs for exclusivity and conformity differ depending on cultural contexts. This is an important contribution to the budding sustainable luxury literature and to the wider literature on sustainability, branding, marketing, and international business.

The results of our study provide practical insights for companies promoting sustainable luxury in Western and Eastern markets. Linking sustainability with doing good, societal contribution, and guilt-free pleasures cumulatively license consumers' pursuit of hedonism and therefore help increase consumers' purchase preference for sustainable luxury. Public relations and promotional campaigns showcasing a luxury brand's fair treatment of workers and suppliers, as well as care for animals and the environment, could evoke positive feelings that consumers are helping society and the environment, making their purchase of sustainable luxury more worthwhile. Nonetheless, the two markets have some differences. In Western economies such as the UK, consumers have doubts about luxury brands' authenticity of being sustainable. To integrate sustainability effectively as an important component, luxury brands could make their sustainable production processes and business practices more transparent. To align with UK luxury consumers, companies could note sustainability as a unique feature, for example by showcasing their innovative design and creative solutions in achieving sustainability.

In Eastern economies such as China, there is a halo effect in luxury consumption. The majority of Chinese consumers tend to assume that luxury brands have adopted sustainable 
practices given their exclusive brand image and price (Lin and He 2017; Cheah et al 2020). Such a halo effect is a double-edged sword. On the one hand, Chinese consumers seem to have higher acceptance levels for sustainable luxury brands. This is good news for luxury brands that have already started integrating sustainability into their products and practices. On the other hand, a high expectation for luxury brands poses a great deal of risk. Any malpractices by luxury brands will lead to massive boycotts in China. This makes it imperative for all luxury brands in the Chinese market to maintain credible sustainable practices. In addition, in promoting sustainable luxury to Chinese consumers, marketers could create and leverage new social norms by educating consumers about sustainability and making purchasing sustainable luxury a trendy and desired lifestyle for the elite, newly rich, and middle class. In doing so, a sustainable luxury brand could attract consumers who are eager to show their social identity by following their reference group.

Despite the insights given, one limitation of our study is that the use of data collected from a survey could be subject to social desirability bias. Respondents might respond according to what they believed to be socially acceptable (Randall and Fernandes 1991; Chung and Monroe 2003; Auger and Devinney 2007). Our data may also be subject to selection bias because those respondents supporting sustainable consumption are more likely to partake in such surveys (Chung and Poon 1994). While we minimized such a bias by putting our questionnaire online and ensuring anonymity in the data collection process, our results must be interpreted with appropriate caution. We have argued that sustainable luxury consumption reduces consumers' guilt so that consumers will derive more pleasure in purchasing expensive luxurious products that are sustainably produced. Guilt is used to support how hedonic needs influences consumers' reaction towards sustainable luxury purchases. Unfortunately, we have not collected data nor developed an instrument to measure "guilt", and hence we could not directly test such an argument. This presents another limitation to this study and opportunities for further research.

Lastly, our study was conducted right before the COVID19 pandemic, which has posed a serious threat to the luxury sector. Since the COVID-19 pandemic, there has been a plunge in consumer confidence as a result of rising unemployment and lower spending power, and disruption of tourists' purchases due to travel restrictions and a fear of possible contagion on planes and cruise ships. Bain \& Company hence forecasted a $25-30 \%$ market contraction in the first quarter of 2020 (D'Arpizio et al. 2020). Irrespective, practitioners and scholars are expecting the luxury retail market to be resilient overall, notably benefiting from the rise of Chinese consumers' appetite for luxury (Khan 2020). In fact, historical data suggest that except for a small dip in 2003 and a larger decline during the recession of 2008-09, the global luxury goods market grew steadily by $6 \%$ CAGR (compound annual growth rate) from 1996 to 2019 (D’Arpizio et al. 2020). Such results suggest that the luxury industry is resilient to economy downturns and market shocks, implying the strong relevance of our results, in the main.

\section{Compliance with ethical standards}

Conflict of interest On behalf of all authors, the corresponding author states that there is no conflict of interest.

\section{References}

Achabou, M.A., and S. Dekhili. 2013. Luxury and sustainable development: Is there a match? Journal of Business Research 66 (10): 1896-1903.

Adams, R. 2011. The utility of prestige: Chinese and American hedonic ratings of prestige goods. Journal of Global Marketing 24 (4): 287-304.

Aliyev, F., T. Ürkmez, and R. Wagner. 2018. Luxury brands do not glitter equally for everyone. Journal of Brand Management 25 (4): $337-350$

Aliyev, F., and R. Wagner. 2018. Cultural influence on luxury value perceptions: Collectivist vs. individualist luxury perceptions. Journal of International Consumer Marketing 30 (3): 158-172.

Anido Freire, N., and L. Loussaïef. 2018. When advertising highlights the binomial identity values of luxury and CSR principles: The examples of Louis Vuitton and Hermès. Corporate Social Responsibility and Environmental Management 25 (4): 565-582.

Athwal, N., V.K. Wells, M. Carrigan, and C.E. Henninger. 2019. Sustainable luxury marketing: A synthesis and research agenda. International Journal of Management Reviews 21 (4): 405-426.

Auger, P., P. Burke, T.M. Devinney, and J.J. Louviere. 2003. What will consumers pay for social product features? Journal of Business Ethics 42 (3): 281-304.

Auger, P., and T.M. Devinney. 2007. Do what consumers say matter? The misalignment of preferences with unconstrained ethical intentions. Journal of Business Ethics 76 (4): 361-383.

Auger, P., T.M. Devinney, J.J. Louviere, and P.F. Burke. 2008. Do social product features have Value to Consumers? International Journal of Research in Marketing 25 (3): 183-191.

Bazi, S., R. Filieri, and M. Gorton. 2020. Customers' motivation to engage with luxury brands on social media. Journal of Business Research 112: 223-235.

Bearden, W.O., R.G. Netemeyer, and J.E. Teel. 1989. Measurement of consumer susceptibility to interpersonal influence. Journal of Consumer Research 15 (4): 473-481.

Bendell, J., and A. Kleanthous. 2007. Deeper luxury. WWF-UK, Godalming. www.wwf.org.uk/deeperluxury/_downloads/Deepe rluxuryReport.pdf. Accessed 21 Mar 2016.

Bendell, J., and L. Thomas. 2013. The appearance of elegant disruption: Theorising sustainable luxury entrepreneurship. Journal of Corporate Citizenship 2013 (52): 9-24.

Berthon, P., L. Pitt, M. Parent, and J.-P. Berthon. 2009. Aesthetics and ephemerality: Observing and preserving the luxury brand. California Management Review 52 (1): 45-66.

Bhattacharya, C.B., and S. Sen. 2004. Doing better at doing good: When, why, and how consumers respond to corporate social initiatives. California Management Review 47 (1): 9-24.

Bian, Q., and S. Forsythe. 2012. Purchase intention for luxury brands: A cross cultural comparison. Journal of Business Research 65 (10): 1443-1451. 
Brundtland Report. 1987. Our Common Future. New York: United Nations World Commission on Environment and Development.

Cervellon, M.C., and L. Carey. 2011. Consumers' perceptions of "green": Why and how consumers use eco-fashion and green beauty products. Critical Studies in Fashion \& Beauty 2 (1-2): 117-138.

Cervellon, M.C., and L. Shammas. 2013. The value of sustainable luxury in mature markets: A customer-based approach. The Journal of Corporate Citizenship 52: 90-102.

Cheah, I., A.S. Shimul, and M.H.M. Man. 2020. Young consumer's attitude toward local versus foreign luxury brands. Journal of Global Fashion Marketing 11 (4): 397-412.

Cheung, C.M., and M.K. Lee. 2010. A theoretical model of intentional social action in online social networks. Decision Support Systems 49 (1): 24-30.

China Daily. 2017. Most Chinese support green consumption, report finds. https://www.chinadaily.com.cn/china/2017-08/24/conte nt_31039222.html. Accessed 01 Sept 2020.

Chun, R. 2016. What holds ethical consumers to a cosmetics brand: The Body Shop case. Business \& Society 55 (4): 528-549.

Chung, J., and G.S. Monroe. 2003. Exploring social desirability bias. Journal of Business Ethics 44 (4): 291-302.

Chung, S.S., and C.S. Poon. 1994. Recycling behaviour and attitude: The case of the Hong Kong people and commercial and household wastes. International Journal of Sustainable Development \& World Ecology 1 (2): 130-145.

Cvijanovich, M. 2011. Sustainable luxury: oxymoron? Available at www.mcmdesignstudio.ch/files/Guest\%20professor\%20 Lucern\%20School\%20of\%20Art\%20\%20and\%20Design.pdf. Accessed 29 Jan 2016.

D’Arpizio, C., F. Levato, S. Fenili, F. Colacchio, and F. Prete. 2020. Luxury after Covid-19: Changed for (the) Good? https://www. bain.com/insights/luxury-after-coronavirus/. Accessed 25 Oct 2020.

D’Arpizio, C., F. Levato, M. Kamel, and J. de Montgolfier. 2017. Luxury Goods Worldwide Market Study, Fall-Winter 2017. Bain and Company. https://media.bain.com/Images/BAIN_REPOR T_Global_Luxury_Report_2017.pdf. Accessed 01 Sept 2020.

Davies, I.A., Z. Lee, and I. Ahonkhai. 2012. Do consumers care about ethical-luxury? Journal of Business Ethics 106 (1): 37-51.

De Angelis, M., F. Adıgüzel, and C. Amatulli. 2017. The role of design similarity in consumers' evaluation of new green products: An investigation of luxury fashion brands. Journal of Cleaner Production 141: 1515-1527.

De Barnier, V., S. Falcy, and P. Valette-Florence. 2012. Do consumers perceive three levels of luxury? A comparison of accessible, intermediate and inaccessible luxury brands. Journal of Brand Management 19 (7): 623-636.

Dekhili, S., M.A. Achabou, and F. Alharbi. 2019. Could sustainability improve the promotion of luxury products? European Business Review 30 (4): 488-511.

Deloitte. 2017. Global Powers of Luxury Goods 2017: The next luxury consumer. Available at https://www2.deloitte.com/content/dam/ Deloitte/global/Documents/consumer-industrial-products/gx-cipglobal-powers-luxury-2017.pdf. Accessed 01 Sept 2020.

Dodds, W.B., K.B. Monroe, and D. Grewal. 1991. Effects of price, brand, and store information on buyers' product evaluations. Journal of Marketing Research 28 (3): 307-319.

Dubois, B., and C. Paternault. 1995. Understanding the world of international luxury brands: The dream formula. Journal of Advertising Research 3 (4): 69-76.

Ehrich, K.R., and J.R. Irwin. 2005. Willful ignorance in the request for product attribute information. Journal of Marketing Research 42 (3): 266-277.

Fauchois, A., and A. Krieg. 1991. Le discours du luxe. Revue Française du Marketing 132: 23-40.
Faure, G.O., and T. Fang. 2008. Changing Chinese values: Keeping up with paradoxes. International Business Review 17: 194-207.

Filieri, R., and Z. Lin. 2017. The role of aesthetic, cultural, utilitarian and branding factors in young Chinese consumers' repurchase intention of smartphone brands. Computers in Human Behavior 67: $139-150$

Filieri, R., Z. Lin, S. D'Antone, and E. Chatzopoulou. 2019. A cultural approach to brand equity: The role of brand mianzi and brand popularity in China. Journal of Brand Management 26 (4): $376-394$.

Fornell, C., and D.F. Larcker. 1981. Evaluating structural equation models with unobservable variables and measurement error. Journal of Marketing Research 18 (1): 39-50.

Gardetti, M.A., and A.L. Torres. 2013. Entrepreneurship, innovation and luxury: The Ainy Savoirs Des Peuple case. The Journal of Corporate Citizenship 52: 55-75.

Gladwin, T.N., J.J. Kennelly, and T.S. Krause. 1995. Shifting paradigms for sustainable development: Implications for management theory and research. Academy of Management Review 20 (4): 874-907.

Gobe, M. 2003. Emotional Identity. Global Cosmetic Industry 171 (2): $26-28$

Goffman, E. 1959. The Presentation of Self in Everyday Life. Garden City, NJ: Doubleday.

Griskevicius, V., J.M. Tybur, and B. Van den Bergh. 2010. Going green to be seen: Status, reputation, and conspicuous conservation. Journal of Personality and Social Psychology 98 (3): 392.

Han, J., Y. Seo, and E. Ko. 2017. Staging luxury experiences for understanding sustainable fashion consumption: A balance theory application. Journal of Business Research 74: 162-167.

Hennigs, N., K. Wiedmann, C. Klarmann, and S. Behrens. 2015. The complexity of value in the luxury industry: From consumers' individual value perception to luxury consumption. International Journal of Retail \& Distribution Management 43 (10-11): 922-939.

Hennigs, N., K.P. Wiedmann, C. Klarmann, S. Strehlau, B. Godey, D. Pederzoli, A. Neulinger, K. Dave, G. Aiello, R. Donvito, and K. Taro. 2012. What is the value of luxury? A cross-cultural consumer perspective. Psychology \& Marketing 29 (12): 1018-1034.

Hofstede, G. 1980. Culture's consequences: International differences in work-related values. Beverly Hills, CA: Sage.

Hofstede, G. 1984. National cultures revisited. Asia Pacific Journal of Management 2 (1): 22-28.

Hofstede, G. 2007. Asian management in the 21st century. Asia Pacific Journal of Management 24 (4): 411-420.

Hofstede, G., and M. Minkov. 2010. Long-versus short-term orientation: New perspectives. Asia Pacific Business Review 16 (4): 493-504.

Jaekel, B. 2019. 2019 luxury spend expected to grow highest in UK. Luxury Daily. https://www.luxurydaily.com/luxury-spend-expec ted-to-grow-highest-in-uk/. Accessed 9 Apr 2019.

Janssen, C., J. Vanhamme, A. Lindgreen, and C. Lefebvre. 2014. The catch-22 of responsible luxury: Effects of luxury product characteristics on consumers' perceptions of fit with corporate social responsibility. Journal of Business Ethics 119 (1): 45-57.

Johnston, A., K. Amaeshi, E. Adegbite, and O.K. Osuji. 2019. Corporate social responsibility as obligated internalisation of social costs. Journal of Business Ethics. https://doi.org/10.1007/s1055 1-019-04329-y.

Kacen, J.J., and J.A. Lee. 2002. The influence of culture on consumer impulsive buying behavior. Journal of Consumer Psychology 12 (2): 163-176.

Kapferer, J.N. 2010. All that glitters is not green: The challenge of sustainable luxury. European Business Review 2: 40-45. 
Kapferer, J.N., and V. Bastien. 2012. The Luxury Strategy: Break the Rules of Marketing to Build Luxury Brands. London: Kogan Page.

Kapferer, J.N., and A. Michaut-Denizeau. 2014. Is luxury compatible with sustainability? Luxury consumers' viewpoint. Journal of Brand Management 21 (1): 1-22.

Kapferer, J.N., and A. Michaut-Denizeau. 2017. Is luxury compatible with sustainability? Luxury consumers' viewpoint. In Advances in luxury brand management, 123-156. Cham: Palgrave Macmillan.

Kapferer, J.N., and P. Valette-Florence. 2016. Beyond rarity: The paths of luxury desire. How luxury brands grow yet remain desirable. Journal of Product \& Brand Management 25 (2): 120-133.

Karaosman, H., P. Perry, A. Brun, and G. Morales-Alonso. 2020. Behind the runway: Extending sustainability in luxury fashion supply chains. Journal of Business Research 117: 652-663.

Keinan, A., R. Kivetz, and O. Netzer. 2016. The functional alibi. Journal of the Association for Consumer Research 1 (4): 479-496.

Khan, M.A. 2020. Luxury business, while resilient, likely to contract $\$ 66 \mathrm{~B}$ to $\$ 77 \mathrm{~B}$ in 2020. https://www.luxurydaily.com/luxur y-business-while-resilient-likely-to-contract-66b-to-77b-in-2020/ Accessed 25 Oct 2020.

Khan, U., R. Dhar, and S. Schmidt. 2010. Giving consumers license to enjoy luxury. MIT Sloan Management Review 51 (3): 12.

Kim, A.J., and E. Ko. 2012. Do social media marketing activities enhance customer equity? An empirical study of luxury fashion brand. Journal of Business Research 65 (10): 1480-1486.

Kline, R.B. 2005. Principles and Practice of Structural Equation Modeling. New York: The Guilford Press.

Labuschagne, C., A.C. Brent, and R.P. Van Erck. 2005. Assessing the sustainability performances of industries. Journal of Cleaner Production 13 (4): 373-385.

Lee, E., M. Edwards, and S., Youn, S., and Yun, T. . 2018. Understanding the moderating effect of motivational values on young consumers' responses to luxury brands: A cross-cultural study of South Korea and the USA. Journal of Marketing Communications 24 (2): 103-124.

Lee, J. 2020. A Decade of Green: China's Top Sustainability Trends in 2020. https://www.orghivemarketing.com/market/decade-green -chinas-top-sustainability-trends-2020/. Accessed 1 Sept 2020.

Lin, Z., and X. He. 2017. The images of foreign versus domestic retailer brands in China: A model of corporate brand image and store image. In Advances in Chinese brand management, 289-315. London: Palgrave Macmillan.

Macchion, L., A. Da Giau, F. Caniato, M. Caridi, P. Danese, R. Rinaldi, and A. Vinelli. 2018. Strategic approaches to sustainability in fashion supply chain management. Production Planning \& Control 29 (1): 9-28.

McKinsey \& Company. 2019. China Luxury Report 2019: How young Chinese consumers are reshaping global luxury. https://www. mckinsey.com/ /media/mckinsey/featured\%20insights/china/ how\%20young $\% 20$ chinese $\% 20$ consumers $\% 20$ are\%20reshapin g\%20global\%20luxury/mckinsey-china-luxury-report-2019-howyoung-chinese-consumers-are-reshaping-global-luxury.ashx. Accessed 25 Oct 2020.

Mititelu, C., G. Fiorani, and S. Mariani. 2014. Cause related marketing: Armani initiative 'acqua for life.' International Review on Public and Nonprofit Marketing 11 (3): 285-305.

Monkhouse, L.L., B.R. Barnes, and U. Stephan. 2012. The influence of face and group orientation on the perception of luxury goods: A four market study of East Asian consumers. International Marketing Review 29 (6): 647-672.

Moss, S., H. Prosser, H. Costello, N. Simpson, P. Patel, S. Rowe, S. Turner, and C. Hatton. 1998. Reliability and validity of the PASADD Checklist for detecting psychiatric disorders in adults with intellectual disability. Journal of Intellectual Disability Research 42 (2): 173-183.

Nunnally, J.C. 1978. Psychometric Theory. New York: McGraw-Hill Book Company.

O'brien, R. M. (2007). A caution regarding rules of thumb for variance inflation factors. Quality \& quantity 41 (5): 673-690.

Oh, M.Y., and J. Ramaprasad. 2003. Halo effect: Conceptual definition and empirical exploration with regard to South Korean subsidiaries of US and Japanese multinational corporations. Journal of Communication Management 7 (4): 317-332.

Passariello, C. 2009. Fighting back against shoppers' guilt. The Wall Street Journal. 30 Oct. https://www.wsj.com/articles/SB100 01424052748704597704574487342734060448 . Accessed 9 Apr 2019.

Pencarelli, T., V. Ali Taha, V. Škerháková, T. Valentiny, and R. Fedorko. 2019. Luxury products and sustainability issues from the perspective of young Italian consumers. Sustainability 12 (1): 245-270.

Peterson, R.A. 2001. On the use of college students in social science research: Insights from a second-order meta-analysis. Journal of Consumer Research 28 (3): 450-461.

Ping, R.A. 2010. How does one estimate categorical variables in theoretical model tests using structural equation analysis? http:// www.wright.edu/ robert.ping/categorical3.doc. Accessed 1 Sept 2020.

Podsakoff, P.M., S.B. MacKenzie, J.Y. Lee, and N.P. Podsakoff. 2003. Common method biases in behavioral research: A critical review of the literature and recommended remedies. Journal of Applied Psychology 88 (5): 879.

Podsakoff, P.M., and D.W. Organ. 1986. Self-reports in organizational research: Problems and prospects. Journal of Management 12 (4): 531-544.

Randall, D.M., and M.F. Fernandes. 1991. The social desirability response bias in ethics research. Journal of Business Ethics 10 (11): 805-817.

Research and Markets. 2017. Global Luxury Goods Market Opportunities and Forecasts, 2022. https://www.prnewswire.com/newsreleases/global-luxury-goods-market-opportunities-and-forec asts-2022---research-and-markets-300391755.html. Accessed 9 Apr 2019.

Roux, E., and J.M. Floch. 1996. Gérer l'ingérable: la contradiction interne de toute maison de luxe. Décisions Marketing 9: 15-23.

Rovai, S. 2016. Luxury the Chinese way: The emergence of a new competitive scenario. Berlin: Springer.

Schramm-Klein, H., J. Zentes, S. Steinmann, B. Swoboda, and D. Morschett. 2016. Retailer corporate social responsibility is relevant to consumer behavior. Business \& Society 55 (4): 550-575.

Seo, Y., and M. Buchanan-Oliver. 2019. Constructing a typology of luxury brand consumption practices. Journal of Business Research 99: 414-421.

Shao, J. 2019. Sustainable consumption in China: New trends and research interests. Business Strategy and the Environment 28: $1507-1517$

Sheth, J.N., B.I. Newman, and B.L. Gross. 1991. Why we buy what we buy: A theory of consumption values. Journal of Business Research 22 (2): 159-170.

Shukla, P. 2011. Impact of interpersonal influences, brand origin and brand image on luxury purchase intentions: Measuring interfunctional interactions and a cross-national comparison. Journal of World Business 46 (2): 242-252.

Shukla, P. 2012. The influence of value perceptions on luxury purchase intentions in developed and emerging markets. International Marketing Review 29 (6): 574-596.

Shukla, P., and K. Purani. 2012. Comparing the importance of luxury value perceptions in cross-national contexts. Journal of Business Research 65: 1417-1424. 
Siu, N.Y.M., H.Y. Kwan, and C.Y. Zeng. 2016. The role of brand equity and face saving in Chinese luxury consumption. Journal of Consumer Marketing 33 (4): 245-256.

Smith, J.B., and M. Colgate. 2007. Customer value creation: A practical framework. The Journal of Marketing Theory and Practice 15 (1): 7-23.

Sperber, A.D., R.F. Devellis, and B. Boehlecke. 1994. Cross-cultural translation: Methodology and validation. Journal of Cross-Cultural Psychology 25 (4): 501-524.

Steinhart, Y., O. Ayalon, and H. Puterman. 2013. The effect of an environmental claim on consumers' perceptions about luxury and utilitarian products. Journal of Cleaner Production 53: 277-286.

Tian, K.T., W.O. Bearden, and G.L. Hunter. 2001. Consumers' need for uniqueness: Scale development and validation. Journal of Consumer Research 28 (1): 50-66.

Torelli, C.J., A.S.B. Monga, and A.M. Kaikati. 2012. Doing poorly by doing good: Corporate social responsibility and brand concepts. Journal of Consumer Research 38 (5): 948-963.

Tse, D. 1996. Understanding Chinese people as consumers: Past findings and future propositions. In The handbook of Chinese Psychology, ed. M.H. Bond. Hong Kong: Oxford University Press.

Tynan, C., S. McKechnie, and C. Chhuon. 2010. Co-creating value for luxury brands. Journal of Business Research 63 (11): 1156-1163.

Vickers, J.S., and F. Renand. 2003. The marketing of luxury goods: An exploratory study. Marketing Review 3 (4): 459-478.

Vigneron, F., and L.W. Johnson. 2004. Measuring perceptions of brand luxury. Journal of Brand Management 11 (6): 484-506.

Wang, C.L., and X. Lin. 2009. Migration of Chinese consumption values: Traditions, modernization, and cultural renaissance. Journal of Business Ethics 88 (3): 399-409.

Widloecher, P. 2010. Luxe Et Développement Durable: Je T'aime, Moi Non Plus? Luxefrancais.

Wiedmann, K.P., N. Hennigs, and A. Siebels. 2009. Value-based segmentation of luxury consumption behavior. Psychology \& Marketing 26 (7): 625-651.

Winston, A. 2016. Luxury brands can no longer ignore sustainability. Harvard Business Review, 8: 1-3.

Wong, N.Y., and A.C. Ahuvia. 1998. Personal taste and family face: Luxury consumption in Confucian and Western societies. Psychology \& Marketing 15 (5): 423-441.

Woodall, T. 2003. Conceptualising "value for the customer": An attributional, structural and dispositional analysis. Academy of Marketing Science Review 12 (1): 1-42.

Yin, S., Y. Xu, and M. Chen. 2013. Consumers purchase decisions and affecting factors on organic food. China Population, Resources and Environment 23 (7): 136-141.

Yin, X., and X. Cao. 2012. An empirical analysis of factors affecting products with low carbon-footprint purchase A based on the survey data of ECO-milk consumption. Journal of Central University of Finance and Economics (in Chinese) 9: 4-9.

Zhan, L., and Y. He. 2012. Understanding luxury consumption in China: Consumer perceptions of best-known brands. Journal of Business Research 65 (10): 1452-1460.

Zhang, B., and J.H. Kim. 2013. Luxury fashion consumption in China: Factors affecting attitude and purchase intent. Journal of Retailing and Consumer Services 20 (1): 68-79.

Zhang, S.S., J. van Doorn, and P.S.H. Leeflang. 2014. Does the importance of value, brand and relationship equity for customer loyalty differ between Eastern and Western cultures? International Business Review 23 (1): 284-292.

Zhang, Y.B., and J.T. Harwood. 2004. Modernization and tradition in an age of globalization: Cultural values in Chinese television commercials. Journal of Communication. 54 (1): 156-172.

Zhou, L., and M.K. Hui. 2003. Symbolic value of foreign products in the People's Republic of China. Journal of International Marketing 11 (2): 36-58.
Publisher's Note Springer Nature remains neutral with regard to jurisdictional claims in published maps and institutional affiliations.

Pengji Wang is an Associate Professor of Business at James Cook University, Singapore Campus. Her research on Strategy, International Business, Circular Economy and Green Marketing has been published in Journal of Business Research, Journal of Business Ethics, International Business Review, Corporate Governance: An International Review, Management and Organization Review, Journal of Cleaner Production, Australasian Marketing Journal, etc.

Adrian T. H. Kuah is an Associate Professor of Business at James Cook University, Singapore Campus, and a Professor (Adj) at Ecole de Commerce de Tahiti in the French Polynesia. Professor Kuah is an awardwinning scholar interviewed by the Financial Times in 2013, Xinhua News Agency, in both 2015 and 2016, and the Cairns Post in 2019. In 2019, he was appointed to partake and represent Singapore's interest in the standardization of ISO/TC 323 Circular Economy at the International Organization for Standardization. His works have appeared in the European Journal of Marketing, Thunderbird International Business Review, Journal of Business Research and Science of the Total Environment.

Qinye Lu is a Senior Lecturer at De Montfort University. Her research focuses on asset pricing, financial econometrics, and international finance. She is also interested in emerging markets, corporate governance, and corporate social responsibility. Her research has been published in high-profile academic journals such as Journal of International Money and Finance and International Review of Financial Analysis. Her paper was awarded the Best Paper Award in the British Accounting and Finance Association Northern Area Group Conference in 2017.

Caroline Wong is the Associate Dean for Learning and Teaching and a Senior Lecturer at James Cook University, Singapore. Her research in knowledge management takes on a multidisciplinary approach that extends into knowledge-based cities, smart cities, creative cities, and creative industries with special focus on Singapore. Her works have been published in the Knowledge of Management Journal and the International Journal of Knowledge, Culture and Change Management, She was a founding member of the International Scientific Committee of the Knowledge Cities World Summit that organized the first Global Knowledge Based Development Week in Monterrey (Mexico) in 2007 and a member of the International Advisory Board on knowledge-based cities (2007-2009). Her presentation of 'Singapore as a knowledge-based city' aptly clinched Singapore the best knowledge city award 2008 in Monterrey, Mexico.

K. Thirumaran is the Academic Head at JCU Singapore Business School, James Cook University. His research focuses on luxury tourism, cultural and heritage tourism, service excellence in hospitality, and training and technology in hospitality. He is the key organizer of the World Luxury Destinations conference 2018 and coined the term 'affinity tourism'. He volunteers as an editorial board member and reviewer in several academic journals and attends numerous MICE events with his students to acquaint them with the industry.

Emmanuel Adegbite is a Professor of Accounting and Corporate Governance and Head of the Accounting Division at Nottingham University Business School. He is visiting professor in management and governance at James Cook University, Singapore. His published works on management accounting, corporate governance, corporate social responsibility, and corporate finance have been widely cited and have, in collaboration, secured around $£ 500,000$ in funding. Recent awards include a Durham University award for Excellence in Research in 2014; 
the Celebrated Nigerian Award UK in 2016; and the International Business Review Best Journal Paper of the Year Award in 2016.

Wesley Kendall is a lawyer, author, and law lecturer. He has taught law and business in the USA, Vietnam, Singapore, and Fiji and has authored several books including The Death Penalty and US Diplomacy (Rowman \& Littlefield, New York 2013), The Language of
Terror (Rowman \& Littlefield, New York 2015) and from Gulag to Guantanamo (Rowman International, London 2015). He received his $\mathrm{PhD}$ from Royal Melbourne Institute of Technology and has published articles in numerous peer-reviewed international journals. 